\title{
Reciprocity and Social Order: What Do Experiments Tell us About the Failure of Economic Growth?
}

KEVIN A. MCCABE

kmccabe@gmu.edu

Interdisciplinary Center for Economic Science, George Mason University, 4400 University Drive, MSN 1B2, Fairfax, VA 22030

\begin{abstract}
This paper makes three observations for policy-makers, interested in promoting economic growth, based on the experimental work done at the Interdisciplinary Center for Economic Science. First, safeguards must be put into place to protect impersonal exchange from our innate desire for personal exchange. Second, policy must take into account the heterogeneity of individual cognitive strategies that are observed in economics laboratories. Third, policy must be test-bedded in economic experiments where the status quo is modeled as an ecologically rational response to the economic environment and the proposed policy change occurs in an environment where individuals have access to a full repertoire of personal exchange behaviors.
\end{abstract}

Key Words: experimental economics, impersonal exchange, social change

JEL classification: $\quad$ C93

\section{Introduction}

Over the course of the last century economists have made significant progress in understanding what makes economies work, and why they fail. What is harder to explain is why humans often get it wrong? Or may be more importantly, why we can't fix things when they are wrong! The answer must ultimately lie in our human nature. But what aspect of human nature is responsible? Is it greed? Conceit? Spite? Love? Ignorance? While all of these may contribute it may be that none of these are necessary or sufficient for economic failure. Instead, research by experimental economists, behavioral economists, neuoreoconomists, economic historians, and institutional economists, suggests that the main culprit is "our natural propensity to truck, trade, and barter" that Adam Smith saw as a basic axiom of human nature.

Adam Smith certainly understood the different motives that individual faced in their personal lives versus the marketplace. Two quotes that appear in Vernon Smith's "Two Faces of Adam Smith" nicely summarize this understanding.

"It is not from the benevolence of the butcher, the brewer, or the baker, that we expect our dinner, but from their regard to their own interest."-Wealth of Nations, 1776.

"How selfish so ever man may be supposed, there are evidently some principles in his nature, which interest him in the fortune of others, and render their happiness necessary 
to him, though he derives nothing from it except the pleasure of seeing it."-The Theory of Moral Sentiments, 1759.

But, how can our propensity to trade cause economic failure? After all trade allows us to capture gains from exchange, and conventional wisdom suggests that greater trade will improve economic performance. The thesis of this paper is that our 'personal propensity' to trade tends to produce exclusive trading arrangements that can and will reduce a society's ability to find and adapt to new trading opportunities.

Douglas North has a life long interest in the following dilemma. Why can't the human race achieve high economic growth throughout the world? The answer, he argues in his most recent work, lies in how the mind perceives the world in which it lives, and how this perception affects economic decision-making that results in path dependent constraints on the dynamics of economic activity. But why is perception so important?

In his study of history North discovered what Adam Smith discovered from his observation of everyday economic activity and Vernon Smith discovered in economics experiments. That is, there is a significant dichotomy between how we perceive the world in terms of our personal lives and how we perceive the world as market actors. North (1990) succulently describes this dichotomy as one between "personal" and "impersonal" exchange. But how do these perceptual differences affect economic growth. For North, the answer is in how our perceptions influence the development of and adherence to our social institutions.

Friedrich von Hayek provides us with a perspective on how perception will affect the development of institutions. He argues that the human mind emerges from the general problem the brain faces of classifying and organizing information. What Hayek terms the sensory order was his response to the rise in dominance of the 'behavioral' school in psychology and a desire to insure this view of the human mind did not over influence economic thinking. Instead he believed that psychology must be understood in terms of the mental order that emerges from the neural connectivity of the brain.

Individuals' emergent mental order then shapes their interaction and through this dispersed interaction begins the ongoing trial and error process of building institutions, and organizations, that result in an emergent, albeit dynamic, social order. Therefore to understand the process of social order one must also understand the emergent mental order that is producing it.

Hayek understood that there were more than one emergent social order that result from human interaction as seen in this paraphrased quote “... we must constantly adjust our lives, our thoughts and our emotions, in order to live simultaneously within different kinds of orders according to different rules. If we were to apply the unmodified, uncurbed rules (of caring intervention to do visible 'good') of the... small band or troop, or... our families... to the (extended order of cooperation through markets), as our instincts and sentimental yearnings often make us wish to do, we would destroy it. Yet if we were to always apply the (competitive) rules of the extended order to our more intimate groupings, we would crush them. (Hayek 1988:18). (Italics are his, parenthetical elaborations are ours in Constructivist and Ecological Rationality in Economics, Smith, McCabe, and Rigdon (2003). 


\section{Experimental Economics: Studying the Extended Social Order}

When Vernon Smith decided to run his first experiments he turned first to the study of market trade. In looking at trade Smith had to devise an institution that would allow individuals to from a market and discover market-clearing prices. The role of private property rights becomes apparent in trying to devise such an experiment and led Smith to also study public goods provision using non-market institutions such as unanimity voting rules. In each instance Smith discovered that the economic problems that subjects faced in his experiments could be solved through the appropriate choice of institutions that would serve to extend individual rationality.

\subsection{Price Discovery}

The supply and demand schedule shown in Figure 1 describes the opportunity cost environment similar to those first studied by Smith. Buyers are each given a schedule of unit values (in this case constant values for 3-5 units; for example, buyer one, B1, has a value of 490 for each of 5 units) indicating how much each unit purchased will be redeemed for in some (in this case U.S.) currency. These redemption schedules induce a willingness to buy units and translate directly into individuals' and aggregate demand curves. Sellers are each given a schedule of unit costs (in this case constant costs for 3-5 units; for example seller $1, \mathrm{~S} 1$, has a cost of 410 for each of five units) indicating how much each unit sold will be charged to the seller in some (in this case U.S.) currency. These cost schedules induce a willingness to sell units and translate directly into individuals' and aggregate supply curves.
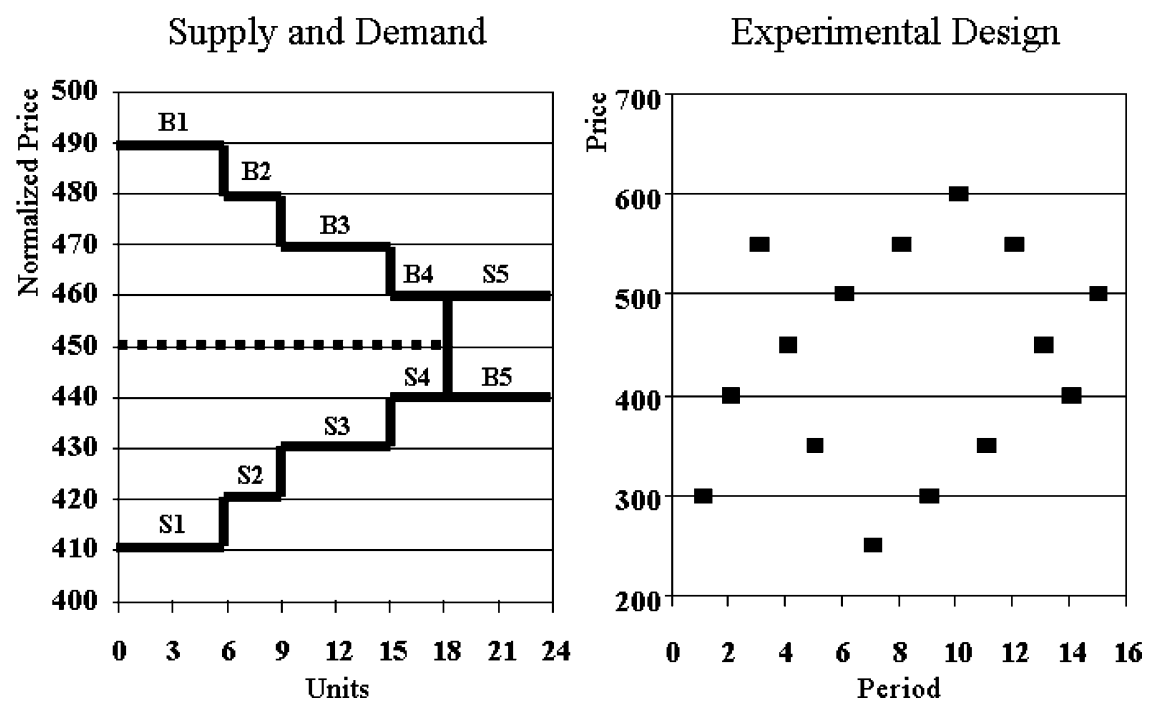

Figure 1. Double auction results and sample environment from boundary experiment. 
Equilibrium price theory predicts that prices in these markets should converge towards a stable equilibrium set of prices, between 440 and 460, such that the quantity sellers are willing to sell just equals the quantity that buyers are willing to buy. However, to test such a theory Smith had to decide how to model the price formation process.

In order to give price theory its best shot, Smith decided to use the "Double Auction." After all, here was a clear price formation institution that was being used by the most modern, and successful, capital markets in the world. Interestingly enough when Vernon imported this institution into his experiments he left behind several key features, such as the preferred positions by 'specialists' and 'brokers,' that we now know are exactly those roles where 'rent-seeking' and personal exchange could reduce the effectiveness of price discovery.

Smith was amazed to find how quickly contract prices converge to the equilibrium prediction. Following up with numerous supply and demand environments that tested the robustness of this result Smith concluded that the double auction often produces price convergence as predicted by market theory. However as part of his research program, Smith also discovered boundary conditions where prices did not converge.

The experimental design (right panel) in Figure 1 shows a sample environment from such a boundary experiment. In this environment the equilibrium price varies randomly from period to period. Adding or subtracting a random constant to values and costs while simultaneously assigning buyers and sellers to different value and cost steps accomplished this, and making the equilibrium price set non-unique.

Figure 2 shows a typical market contracts for this environment. As can be seen contract prices are not converging, however, average price predicts equilibrium quite well and market

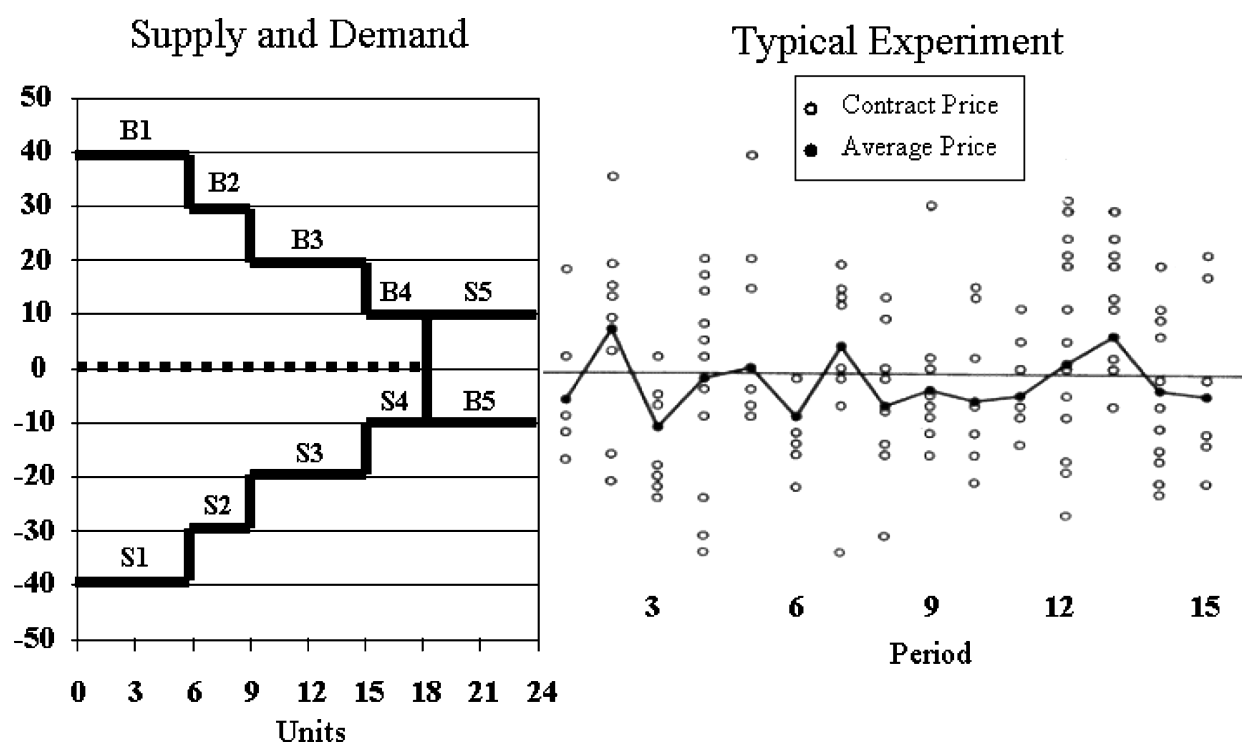

Figure 2. Typical double auction results. 
efficiency was around $90 \%$. The net result is high-efficiency but also high price discrimination. This led McCabe, Rassenti, and Smith (1992) to ask the following question. Can we design an alternative to the double auction that would achieve the same level of efficiency without the price discrimination?

This question is an Economic Systems Design question. Research proceeds in three steps. First, hypothesize different price discovery rules, second, implement these rules in economics experiment, and third, test bed these rules in a common economic environment. Test bedding requires a pre-specified performance measure or measures. In this case, performance measures included market efficiency (percent of maximum surplus obtained), and contract price variance.

Smith and his colleagues decided to handle price variance by choosing call market rules that would produce a single market price for all contracts at one point in time. They then compared several call market rules in the environment shown in Figure 1. One of these rules sets consisted of two synchronized English clocks that produced a two-sided version of the usual one-sided English auction. The resulting Double English auction, or EE for short, was expected to perform at the same high levels of efficiency observed in its one-sided cousin, and indeed there was some support in theory in the one unit per-person case. However, as shown in Figure 3, the double English option performed far worse than any other auction tested, including the double auction (DA) baseline.

Figure 3 shows efficiency comparisons for five different price discovery rules in three panels indicating early (periods 1-5), middle (periods 6-10), and late (periods 11-15) stages of the experiments. The first two bars of each panel compare two institutions that are used 'on-the-ground,' the double auction (DA) ant Tatonnement (TT). As can be seen these two auctions perform quite similarly. The next two bars compare two clock variations, EE, and the two-sided Dutch auction, called Double Dutch, or DD for short. As can be seen DD performed the best; and was significantly better than the double auction in all three panels.

\section{Efficiency Comparisons}

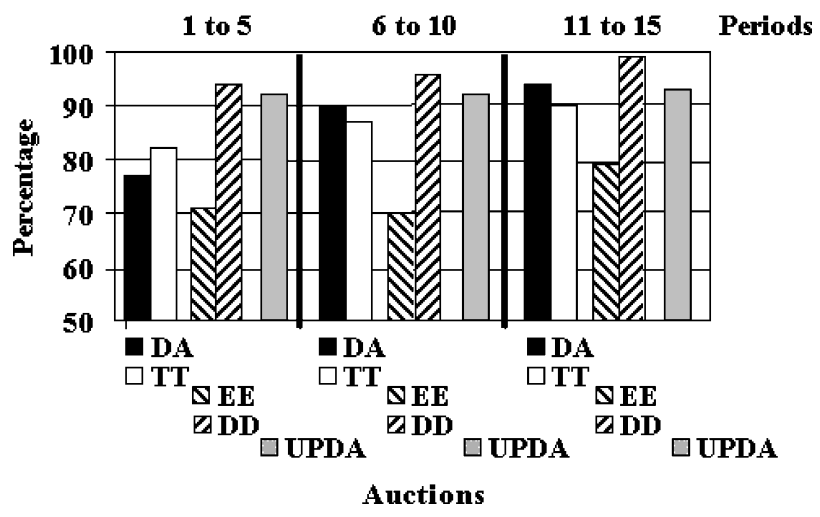

Figure 3. Comparing price discovery rules. 
Another auction that was designed in the laboratory and produced high market efficiencies was the Uniform Price Double Auction, or UPDA for short. However, several variations of this auction had to be tested before the right pricing rules were found. Indeed, both the DA rules and Tattonement rules were studied extensively in the laboratory in order to discover the relative importance of the 'on-the-ground' implementation decisions. This research illustrates the problem of designing a set of rules to implement the basic understanding that a competitive market will reach $100 \%$ efficiency through a process of price discovery where prices converge to market clearing prices.

\subsection{Property Rights}

In the late seventies and early eighties Vernon Smith further developed his methods for experimental economics and economic systems design by studying how property rights failures could be handled through institutional design. In this research Smith proposes and tests an institution he calls the auction method. Bergstrom reviews this work in detail in his Journal of Economic Perspectives article on Smith.

The auction method was designed to implement Wicksell's principle of unanimity. The institution works as follows. Each person privately proposes a quantity of the public good, and a willingness to pay. The institution then proposes the mean quantity of public good, and individual cost shares based on their willingness to pay. If everyone agrees, the public good is provided at the cost shares agreed-upon, otherwise individuals are asked to submit new proposals.

Smith's research can be seen as both, a prescriptive exercise in institutional design, and an investigation into the feasibility of emergent solutions to property right issues.

At roughly the same time Maxwell and Ames were developing the prototype institution for studying free-riding behavior in public goods environments, which they called the Voluntary Contributions Mechanism, or VCM for short.

In the VCM, a number of people, $N$, are each given a number of tokens. They are then told that each token can be contributed to a private account, which will convert each token contributed to a penny in U.S. cash, or they can contribute tokens to a public fund, which will convert each token contributed to more than a penny, say $R$ pennies. In general $R$ and $N$ are chosen so that the marginal per capita return, $r=R / N$, is less than 1 . Subjects are further told that the return from tokens contributed to the private fund will go directly to them while the return from contributing to the public fund will be split equally resulting in a return of $r$.

Game theory predicts that as long as the marginal per capita return on the public fund is less than one, then each individual has a dominant strategy to contribute nothing to the public fund. However, Isaac and Walker find that at least some individuals are willing to contribute to the public good, and that willingness to continue increases with the level of the marginal per capita return.

Figure 4 shows some data from classroom experiments that I have run from 1991 to 1995 with undergraduate students from various universities. In all these cases, $N$ equals 10, and $R$ equals 3 . The first three periods replicates Isaac and Walker quite nicely with contributions starting around $50 \%$ and deteriorating over time. In the next three periods subjects are 


\section{Previous Voluntary Contributions Lab Results (10 teams)}

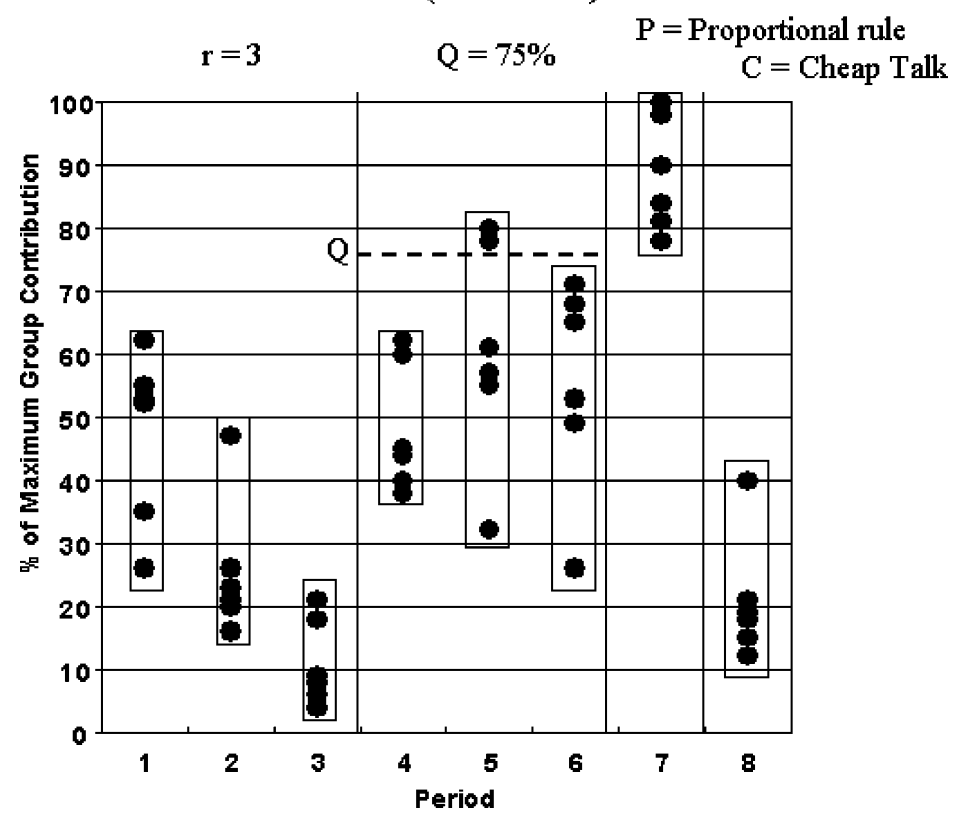

Figure 4. Previous voluntary contributions.

told that contributions must sum to a target level of 750, otherwise contributions will be returned and can then be invested in the private account. These periods replicate Andreoni's Nash implementable step level public goods experiments. Contributions do increase, but usually not to the predicted Nash equilibrium of 750. Period seven shows that contributions will increase dramatically if the return from the public fund is distributed in proportion to people's giving, but this is equivalent to privatizing the public fund, and a similar to the privatization of firm's in capital markets. Finally, period eight is run just like period three except now people are allowed to communicate to the group the benefits to cooperation; alas, this is seen correctly as cheap talk.

Notice that Smith's auction method gives subjects feedback within a period, while the voluntary contributions mechanism does not. This led Bob Dorsey to examine a 'real time' VCM in his dissertation. Dorsey found that people gave more when they saw what others were contributing to the public fund as long as contributions can only increase. If people could decrease their contributions then contributions themselves were seen as cheap talk, and the real-time VCM did no better than the static VCM. Kurzban et al. (2002) replicated Dorsey's findings and then examined how different information conditions about others giving affects contributions. They used $N$ equals five person groups with a marginal per capita return equal to $1 / 3$. They find that the best information condition is to provide subjects with only the lowest current contribution. Results for five, 10 period, runs of this experiment are shown in Figure 5. Notice that while contributions increase in three of the five runs, 


\section{Percentage of Maximum Contribution to the Public Good in a Real Time VCM with Low Contribution Revealed}

$\%$

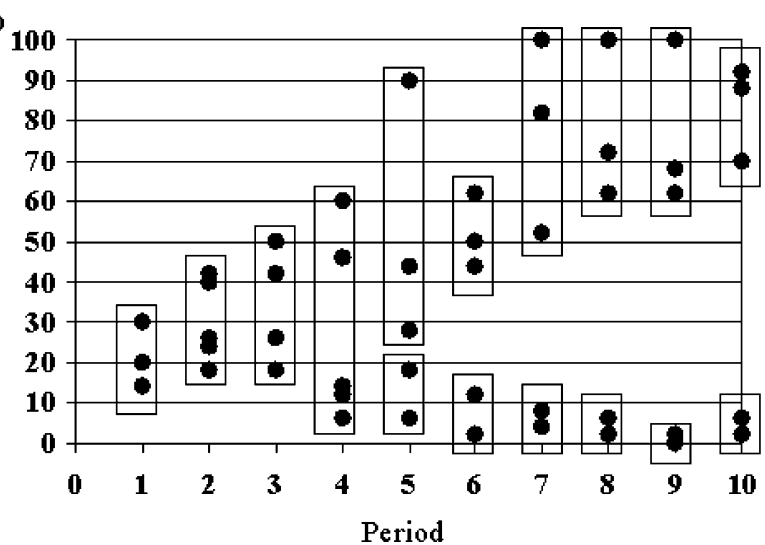

Figure 5. Percentage of maximum contribution to the public good.

there is a fairly high variance between periods for the same run, and within a period across runs. There is still much to be learned about how to increase provisions to public goods through private incentives.

\subsection{Lessons Learned}

In Section two, we have looked at both, institutions for price discovery in an informationaldecentralized private goods environment, and institutions for public goods provision in an informational decentralized public goods environment. In the former we were guided by a competitive equilibrium theory, while in the later we were guided by Nash equilibrium theory. In both cases, institutions are picked based on their ecological rationality as observed in the real world.

Five lessons follow from these experiments. Lesson one; ecologically rational institutions perform better than theoretical institutions in the laboratory. Lesson two; competitive equilibrium predicts robustly in a variety of private property and private information environments, when an appropriate price discovery institution is chosen. Lesson three; Nash equilibrium is not as robust, predicting well in some environments, but not in others. Lesson four; institutions are built incrementally by trial and error. Lesson five; the laboratory can be used as a low-cost test-bed to improve this process, and to examine the consequences of proposed rule changes.

\section{Behavioral Economics: Studying the Personal Order}

Personal order emerges as individuals interact through their innate cognitive capacities for personal exchange augmented by the creation of roles and the formation of expectations 
Double Blind (SB) vs. Single Blind (DB)

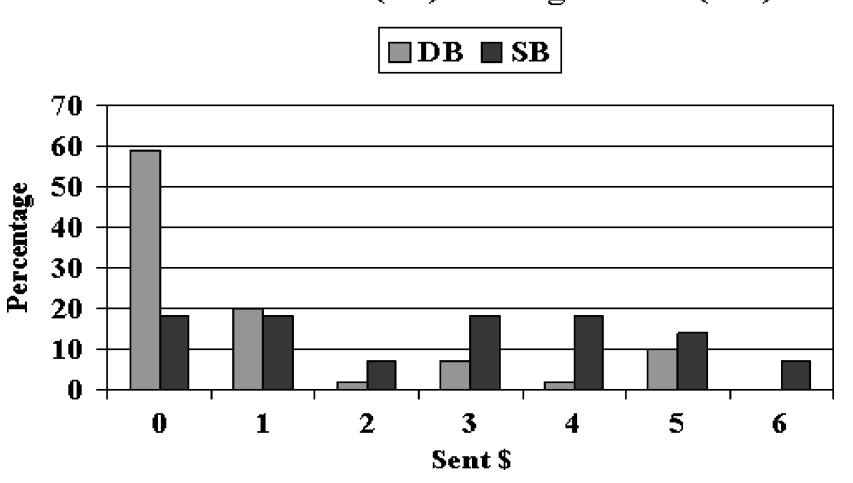

Figure 6. Dictator game: Double blind vs. single blind.

on these roles that augment this form of exchange. Both past interactions, and expectations about future interactions influence how an individual will fare in personal exchange. As a consequence individuals are strongly aware of what other people learn and infer about their social behavior.

\subsection{Dictator Games as Private Interest Baselines}

The dictator game provides a clear example of social awareness. In the dictator game a subject is given $\$ 10$ in $\$ 1$ bills and is asked to decide how much, if any, to send to an anonymous counterpart. If people prefer more money to less, and act in their own selfinterest, then we would predict that they would keep the entire $\$ 10$.

The black bars in Figure 6 show the distributions of amounts given by 24 dictators. Notice that only $20 \%$ of the dictators kept all the money. Why is this so? This treatment is called single-blind since even though the dictator's counterpart didn't know the identity of their dictator, the experimenter did know the identity of this person. Hoffman, McCabe, and Smith (1996) hypothesized that dictators did not keep more because they were aware of this fact. To test this hypothesis they ran a double-blind treatment where the experimenter could not identify individual dictators decisions. The results for this treatment are shown as the gray bars in Figure 6. Now almost 60\% of the dictators keep all the money. This threefold increase provides strong support for the social awareness hypothesis.

\subsection{Ultimatum Games and Personal Sanctions}

The Ultimatum game, first introduced by Guth, Schmittberger, and Schwarze (1982), provides us with examples of conciliatory behavior and negative reciprocity. Player 1 must decide how to split a fixed amount of money (say \$10). For example, player 1 can propose a split of $\$ 9$ for player 1 , offering $\$ 1$ to player 2 , or $(9,1)$. However, a proposal of $(5,5)$ would be seen as more conciliatory. Once player 1 proposes a split, player 2 can either accept or 
reject. If player 2 rejects, then both players earn zero; otherwise, the players earn the split proposed by player 1 .

How should player 1 split the money? If player 1 proposes $(9,1)$, this is better for player 1 than the proposal $(5,5)$. But is player 2 more likely to reject the $(9,1)$ proposal, in which case player 1 ends up with nothing? At what level should player 2 reject player 1's offer, since the rejection of even $(9,1)$ means that player 2 must give up $\$ 1$ ? The subgame perfect equilibrium prediction is that player 2 should accept any positive offer, and player 1 , reasoning this, should offer $(9,1)$.

When Guth, Schmittberger, and Schwarze first ran this experiment with cash-motivated subjects, they observed that the modal proposal was to split the money 50-50. This result has now been replicated a large number of times, including by Forsythe et al. (1994), who then compare offers in ultimatum games to those in dictator games to determine if the 50-50 proposals in ultimatum games are largely a consequence of player 2's threat to reject.

Forsythe et al. find a significant reduction in offers in the dictator game compared to the ultimatum game. They conclude that it is the threat of rejection by player 2 that leads player 1 to follow the conciliatory 50-50 split. Since negotiating mutually agreeable splits is essential to every exchange, and since exchange is voluntary and therefore the threat of rejection is always possible, it seems clear that negative reciprocity plays an important role in economic exchange.

Following up on the Forsythe et al. results, Hoffman et al. (1994) look at how contextual effects can shape expectations about the first mover role as predicted by social exchange theory (see Brewer and Crano 1994). According to social exchange theory, subjects form their expectations on the "fairness" of an exchange using three norms: equity, equality, and reciprocity. Equity implies that individuals who contribute more to a social exchange should gain a larger share of the returns. When everyone's contribution is the same, equality implies that everyone should share equally in the benefit. Reciprocity implies that if one individual shares with another individual, the second individual must reciprocate as soon as possible.

Hoffman and her colleagues examine two treatments: property rights on first and second mover roles and socially defined exchange roles for both first and second movers. In the property-rights treatment, subjects were assigned the role of first or second mover either randomly (RANDOM) or by winning the right to be first mover in a knowledge contest (CONTEST).

In RANDOM, Hoffman et al. predict that the equality norm should be invoked, while in CONTEST, the winners being told they had "earned the right" to be first mover is predicted, by the equity norm, to create a role that entitle the person assigned to that role to a larger share of the money.

In the exchange roles treatment, first movers were referred to either as decision-maker 1's (DIVIDE) or as sellers (EXCHANGE). Second movers were referred to as either decision maker 2's (DIVIDE) or as buyers (EXCHANGE). In DIVIDE, decision maker 1 was asked to divide the \$10; while in EXCHANGE, a seller was asked to make a price decision against a known buyer's valuation of $\$ 10$ amounting to an offer to split the money. Second movers were treated similarly. In DIVIDE, decision maker 2 was asked to accept or reject the offer; 


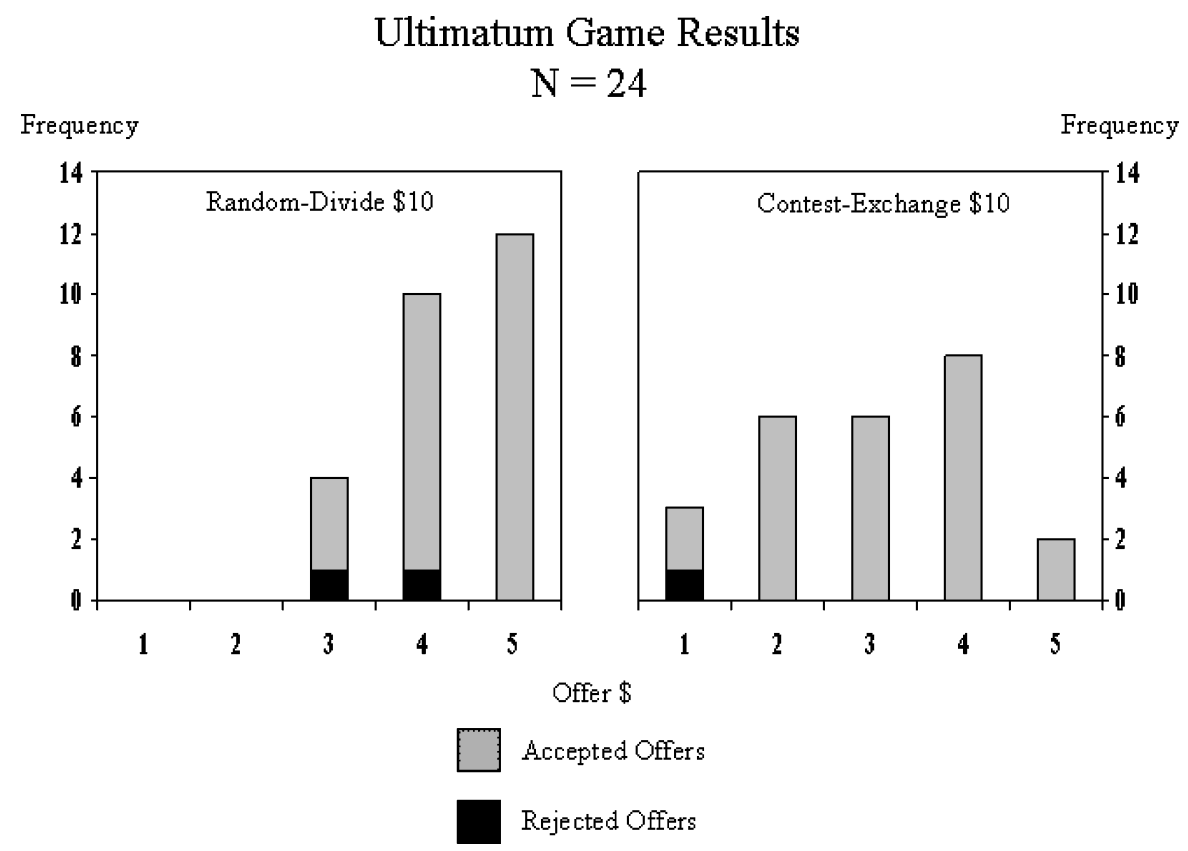

Figure 7. Ultimatum game results.

while in EXCHANGE, a buyer was asked to make a buy, or no buy, decision, amounting to an accept, or reject, decision.

Since sellers are entitled to set prices in most modern retail economies, Hoffman et al. predicted that the equity norm might imply a greater share for sellers in case two. In contrast, the use of neutral terms, such as decision maker, was predicted to invoke the equality norm.

Results are shown in Figure 7. As shown on the left, Hoffman et al. first replicate the Forsythe et al. results; i.e., RANDOM/DIVIDE, finding over 50\% of the offers were at $50-50$ with a mean offer to decision maker 2's of \$4.37. By comparison, on the right, in CONTEST/EXCHANGE, which was predicted to have the strongest equity norm effect, less than $10 \%$ of the offers were at $50-50$ with a mean offer to decision maker 2's at $\$ 3.08$. In both cases rejection rates were low, about $10 \%$. Furthermore, even though offers to the second mover were much lower in CONTEST/EXCHANGE, rejection rates were at the same level as those in RANDOM/DIVIDE. That rejections did not increase in the CONTEST/EXCHANGE treatment can be explained if second movers had accepted the first movers' right to claim more.

\subsection{Investment Games and Interpersonal Trust}

Imagine you have been invited to an experiment where you and your counterpart have each been promised $\$ 10$ as a show up fee. When you show up you are seated privately and asked 
to read a set of instructions about today's experiment, and you learn that you will have the opportunity to send none, some, or all of your $\$ 10$ show up fee to an anonymous person also in the experiment. You then read that whatever amount of money you send to the other person will triple when it gets to them, so if you send all \$10 they will get $\$ 30$. At this stage in the instructions you may be asking yourself, "am I expected to provide charity to this other student?"

Reading on, you learn that the other person will have the opportunity to send none, some, or all, of the tripled amount they have received back to you. Furthermore, you read that the other person has read the same instructions as you and knows the dilemma that you face. Maybe now you are asking yourself, "should I trust my counterpart and send \$10?" How much money will you send?

Berg, Dickhaut, and McCabe (1995) first ran this experiment at the University of Minnesota. The conventional wisdom among economists was that the second decision maker should keep all the money, out of a myopic sense of self-interest, and that first movers should recognize this and send nothing. To give the conventional wisdom its best shot the experiment was run "double blind" meaning the experimenter did not know the identity of the subjects that made specific decisions. The surprise, shown in Figure 8 top panel, is that all but two of the 32 first movers send some amount of money, with two-thirds sending $\$ 5$ or more, and about half of these enjoying reciprocity from their counterpart.

Next, Berg et al. provided 28 additional pairs with a summary of the subjects experience in the top panel, and with this additional information had them play one-shot investment

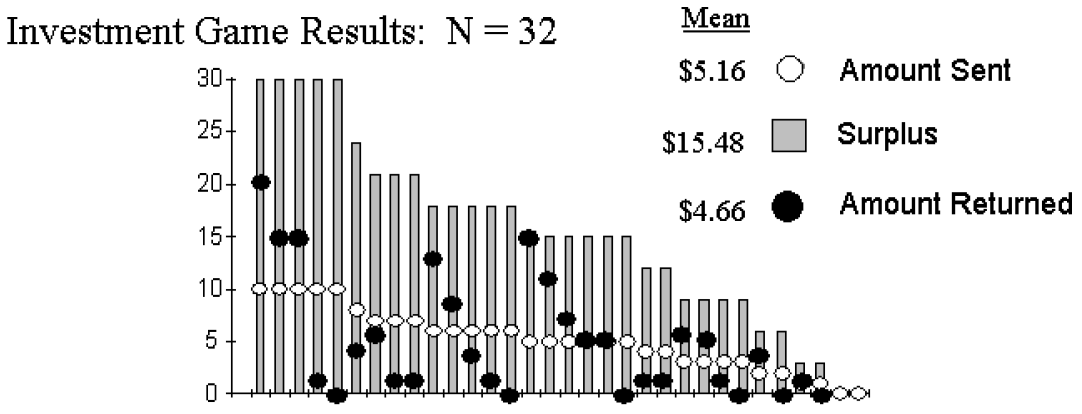

Social History Results $\mathrm{N}=28$

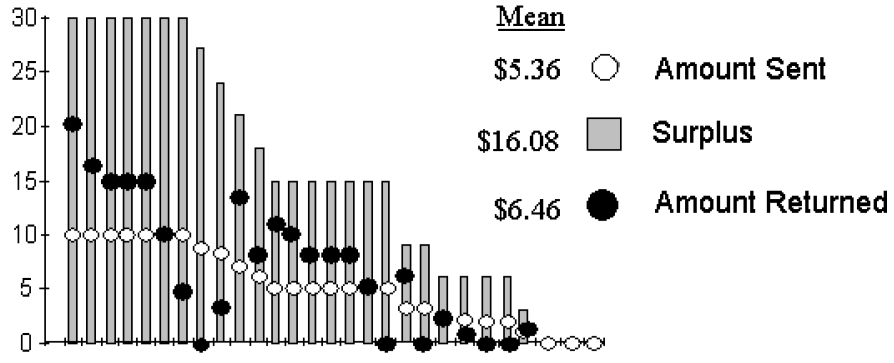

Figure 8. Investment game results. 
game. They conjectures that subjects would use this additional information in an attempt to understand what the social convention (or norm) was in an experiment which can clearly be interpreted as one involving trust and reciprocity but where subjects had no prior experience.

The results from their social history treatment are shown in the bottom panel of Figure 8, where we can see that social history does play a role in shaping individuals expectations. While the amount sent, i.e., our measure of trusting behavior, increases a little bit, the amount returned, i.e., our measure of trustworthy behavior, increases dramatically.

Next you can ask yourself how would you behave if you were going to play the investment game twice with the same person. You will play the same role both times (either first or second mover), and each game will be played independently of the other except you will each know what the other did the first time. If you are first mover should you trust the other person more or less the first time? What about the second? If you are second mover should you reciprocate the first time? What about the second?

Complete information noncooperative game theory again makes a clear prediction. Since the second play is just a one-shot game player two should send back zero, and therefore, player one should send back zero. But, by backwards induction player two now has nothing to gain by sending back anything in the first play, and thus should send nothing, and therefore, player one should send nothing in the second period. But we already know this prediction is wrong for the one-shot game.

Using this information we can develop an incomplete information game theoretic prediction. In this case Dickhaut and McCabe (1997) develop a model where some player one's and two's are predisposed to be trusting, and trustworthy, to begin with. In this case self-interest might be moderated by a desire to earn more by building a reputation as a reciprocator by acting more trusting and/or trustworthy in the first play of the game and then reverting to self-interest in the second play. Player one's trying this strategy would send $\$ 10$ the first time and nothing the second, while player two's following this strategy would reciprocate the first time and send back nothing the second.

The results from the two period investment game are shown in Figure 9. As predicted cooperation between subject pairs is much higher in the first period than in the second. This suggests that subjects have built in beliefs that there will be trusting and trustworthy types in this population. Furthermore a surprise result emerged. Most subjects split 50-50 the amount they received, e.g. $\$ 30$ was frequently split $\$ 15-\$ 15$. So it seems that people naturally expect the social norm of equal split among trustworthy types of people.

\subsection{Lessons Learned}

In section three we have looked at the implications of a personal social order for behavior in the ultimatum and investment games. We find that personal order emerges through the decision-making roles that people play, and the expectations that form around these roles. Furthermore in the laboratory, roles and expectations are relatively malleable by manipulating what subjects see and believe.

The following lessons can be learned from these experiments. Lesson one, as seen in the dictator and investment games, people are cognizant of both what others may learn of their past behavior, and the future potential of continued personal relationships. Both factors 
Two Period Investment Game Results: $\mathrm{N}=23$
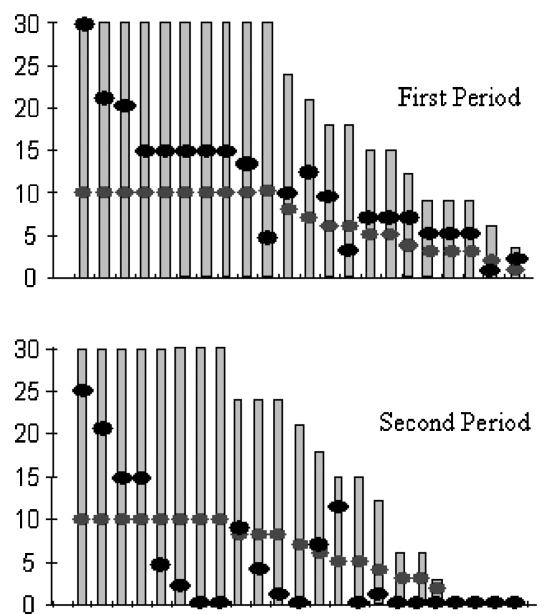

Figure 9. Two period investment game results.

then serve to moderate one's immediate self-interest. Lesson two, as seen in ultimatum games, people are willing to punish others when they failed to live up to expected norms, and even when such punishment is personally costly. This willingness to punish is clearly expected by first movers who often then split 50-50. Lesson three, expectations about roles can easily be modified through the establishment of property rights, or appealing to well-defined roles, such as buyer or seller, the people are already familiar with. Lesson four, as seen in investment games, people are willing to trust others, and reciprocate the trust of others, even when trust is risky and reciprocation is costly. Furthermore, norms for trustworthiness are easily strengthened by social history. Lesson five, the strategic building of reputations can occur quite quickly when the underlying types are ecologically rational, and therefore expected to exist.

\section{Neuroeconomics: Studying the Sensory Order}

Neuroeconomics is the study of how the embodied brain interacts with its external environment to produce a mind capable of interacting with other minds to produce economic behavior. Modern advances in the study of the brain now allow us to pursue Hayes's original goal of understanding how the sensory order within the mind leads to social order between minds. Neuroeconomics helps us understand the biological foundations of economic behavior that leads to the variation in individual strategies that are commonly observed in most economic environments, and the developmental of institutions that act as extensions of our individual and collective mental efforts.

To better understand how the brain produces a mind capable of personal exchange the first step was to simplify the games discussed in subsection three in order to use neuroimaging 
One-Shot Trust Game
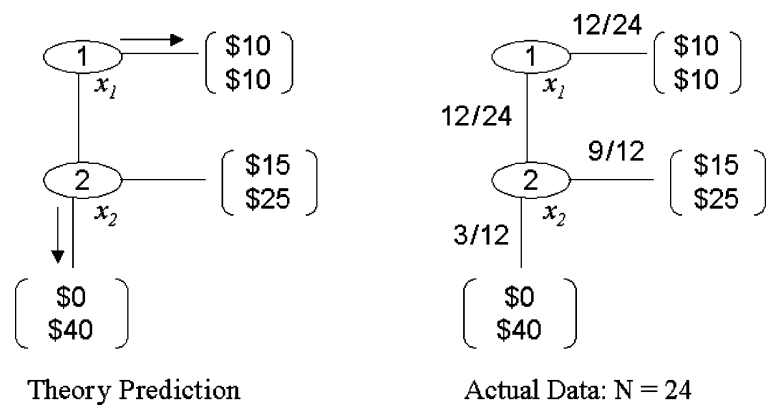

Figure 10. One-shot trust game.

techniques. At the same time, these new games provide us with not exact replications of the earlier results on reciprocity thus demonstrating the robustness of this behavior in the laboratory.

\subsection{The Trust Game}

The trust game in the left panel of Figure 10 is a simplification of the original investment game. In this game player one can choose to move right getting both players $\$ 10$ or player one can choose to move down, the equivalent of sending $\$ 10$ in the investment game. If player one moves down, player two can choose to move down, keeping all the money, and resulting in zero for player one and $\$ 40$ for player two, or player two can move right, splitting the $\$ 30$, resulting in $\$ 15$ for player one and $\$ 25$ for player two (\$15 plus $\$ 10$ ). Moving down by player one is interpreted as a trusting move while moving right by player two is interpreted as a trustworthy response.

The results from this game are reported in McCabe and Smith (2000). In this experiment 12 subjects were recruited in each session. Subjects were randomly assigned to either the player one role, or the player two role. Once subjects were assigned their roles they played the game once. A total of 24 pairs of data were collected. Exactly half of the player one's played down, the sending an average of five dollars, which is comparable to the investment game. Of the 12 player twos who got to respond, $75 \%$ played right.

McCabe and Smith followed up on this by looking at 28 pair of graduate students who played a two period trust game using the same play rules as the two period investment game. The main difference is that the graduate students had all been trained in game theory in different universities throughout the world. The two period trust game has the same complete information Nash equilibrium prediction as the two-period investment game, i.e., by backwards induction player one should move right in both periods, but again allows for an incomplete information prediction where player's strategies take into account the existence of reciprocal types. In this case, subjects are predicted to increase their cooperation in period one and decrease it in period two. 


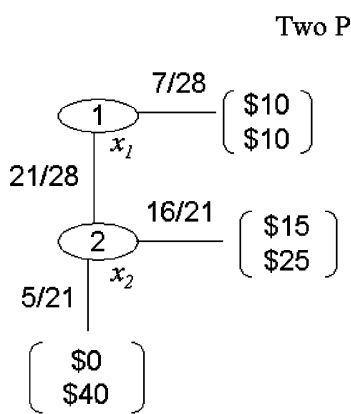

Period One

wo Period Trust Game

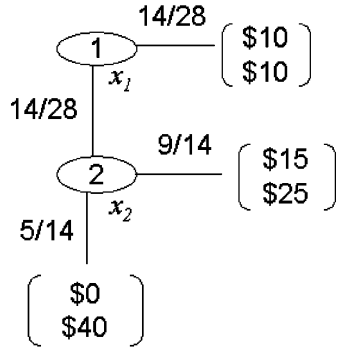

Period Two

Figure 11. Two period trust game.

Figure 11 shows the results from this experiment. The left panel shows the results for the first period, the right panel shows the results for the second period. In period one $75 \%$ of player one's now move down, while $76 \%$ reciprocate. In contrast period two reverts back to the one period result with only $50 \%$ moving down, and $64 \%$ reciprocating.

\subsection{Evolutionary Accounts of Goodwill Accounting}

In McCabe and Smith (2001), we develop a theory of personal exchange that we call goodwill accounting. This strategy tracks the amount of goodwill that one person has with another and weighs the amount of goodwill against the risk of cooperation. We hypothesize that goodwill is accounted for implicitly through the experience of affectively enhanced memories of previous exchange outcomes with particular individuals. We showed through a series of computational simulations that such a mechanism could lead to reasonably stable personal exchange relations as shown in Figure 12.

Notice that the solid lines indicate strong personal exchange ties that have been built up over the course of one simulation with randomized initial conditions.

While sensitive to initial conditions, it was common to see a pattern of connections emerge that allowed indirect exchange between larger groups of persons with some players playing more central roles. It was also common to see exclusionary relationships developing. Notice that $3,11,12$, etc. have no trading partners while $4,5,16,25$ form a smaller trading group.

If personal exchange develops along theses paths we would expect there to be some invasion by persons/strategies that are good at getting around these affective memory responses. Sociopaths represent one such group, but not quite as extreme are people who score very high on the Mach IV instrument, an instrument designed by social psychologists to measure how instrumentally a person would treat others.

Gunnthursdottir, McCabe, and Smith (2002) predicted that High Machs would be less trustworthy in one-shot trust games because they had developed strategies to manage their standing with others even though they are not generally cooperative. This could be done by having high compensatory skills, such as surgeons, or by moving around a lot. 


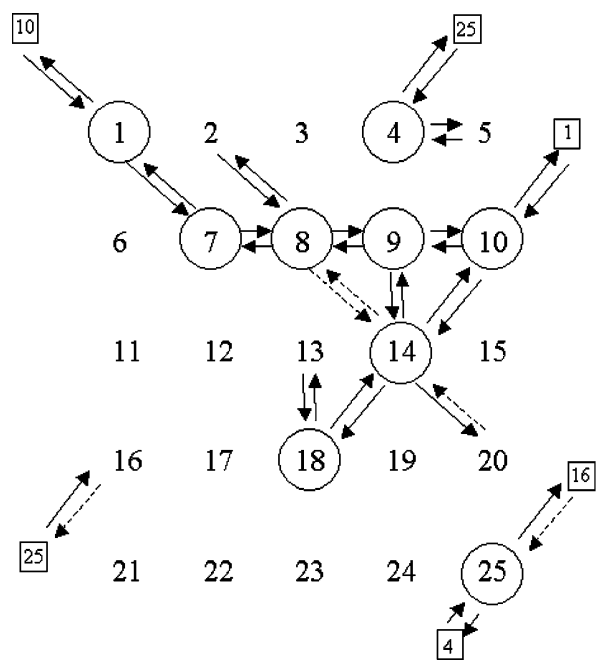

Figure 12. Personal exchange relations.

\section{Mach Score Data}

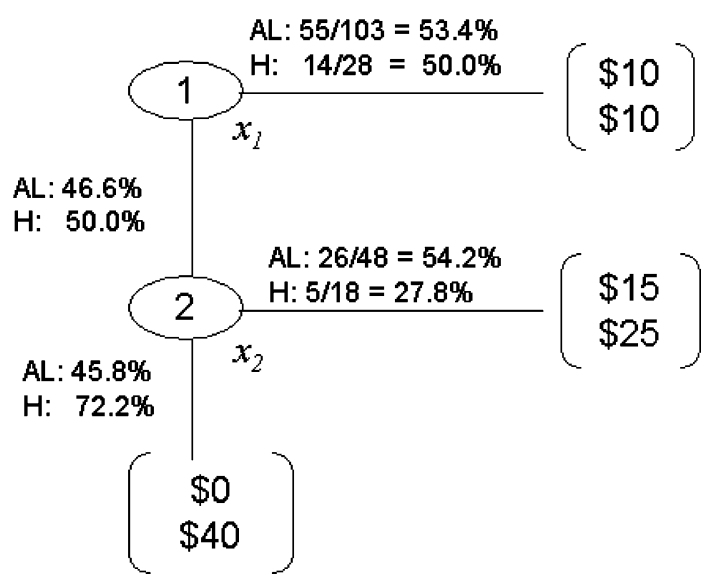

Figure 13. Mach score data

Gunnthursdottir et al. got twelve hundred Mach IV score results from college freshmen in psychology courses and then independently recruited High, Average, and Low Machs for economics experiments. Subjects were recruited through an anonymous email system and did not know they were recruited based on their Mach score. The results from this experiment are shown in Figure 13. When subjects arrived they were matched into pairs H-H, H-A, H-L, A-H, A-A, A-L, and L-H, L-A, L-L. And then played the trust game shown in Figure 13. 


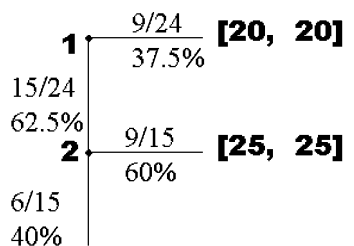

[ 15, 30]

Voluntary Trust Game

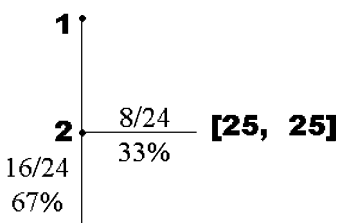

$[15,30]$

Involuntary Trust Game

Figure 14. Voluntary and involuntary trust game results.

As predicted High machs are twice as likely to defect in one-shot games, but are as trusting as anyone else in the subject population.

\subsection{Theory-of-Mind}

An important feature of the goodwill accounting strategy is its use of a theory-of-mind capability that allows a better coordination of reciprocal intentions between trading partners. A theory-of-mind capability is postulated by cognitive psychologists to be an important feature of normally developed minds since it seems to be missing in the minds of autistics, see Baron-Cohen (1985), and more recently Gallagher and Frith (2003).

To test whether a theory of mind may be important in playing trust games McCabe, Rigdon, and Smith (2003) compare behavior in the voluntary trust game, shown in the left panel of Figure 14, to behavior in the in the involuntary trust game shown in the right hand panel.

As shown in Figure 14, Player 2's are twice as likely to make the trustworthy move (right) in the Voluntary Trust game compared to the involuntary trust game. We hypothesize that the eight of twenty-four who move right in the Involuntary Trust game did so because their past experience has primed them with a strong positive belief that others are trusting so that their prior is that player one's are trusting and they should be trustworthy in return. The additional subjects who move right in the Voluntary Trust game do so because they realize that player one has given up $\$ 20$ in order to make them both better off at $\$ 25$ and for this reason believe (conditional on the information revealed by the move) that player one is trusting and they should be trustworthy.

\subsection{Imaging the Brain of a Cooperative Mind}

This research led to the question can we image the brain as it makes cooperative decisions to see if theory-of-mind may be at work? McCabe, Houser, Ryan Smith, and Trouard (2001) ran an fMRI experiment where subjects played either another subject or a computer in different reciprocity games as either player one or player two. In this research we hypothesized that an important feature of a mind capable of personal exchange is its ability to gain cognitive control over immediate desires, that is, to delay gratification in favor of larger mutual gains. 
Differences in Brain Activity While Playing Cooperatively With a Human vs. Playing Cooperatively With a Computer

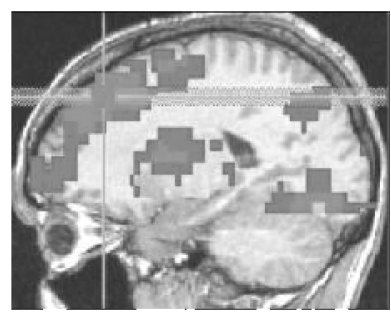

Human Counterpart

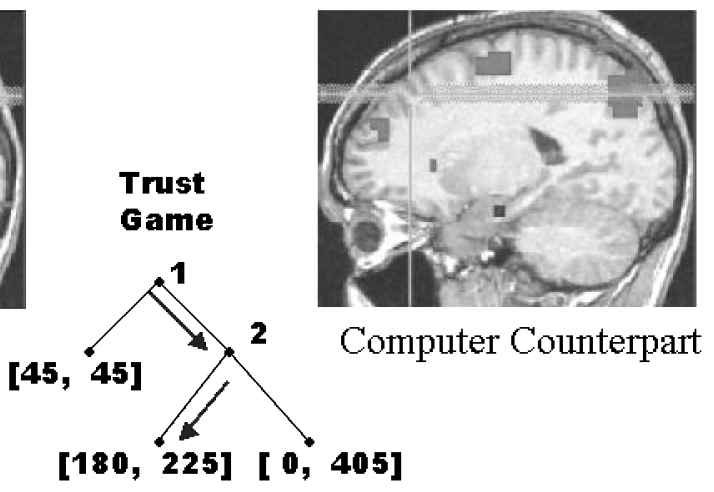

Decision Maker 1 is in the MRI scanner and is choosing in both cases to move right. Decision maker 1 is 'trusting' the human counterpart (decision maker 2), but making a 'calculated' response to the computer which is known to move left $75 \%$ of the time as decision maker 2 .

Figure 15. Differences in brain activity.

To do this, we predicted that the brain would use pre-frontal regions associated with theoryof-mind to reason about the other player's interest in cooperation and would then invoke frontal control mechanisms to make trusting and trustworthy responses.

Figure 15 shows the activation of a typical subject cooperator as they were cooperating with another human (left panel) vs. playing a computer (right panel).

Notice the much stronger pre-frontal and frontal activations associated with playing the human. Noncooperation against another human looked like the right panel, i.e., the noncooperator subjects brain activity looked identical whether they were playing a human or a computer suggesting that a noncooperator need only treat another human being instrumentally, like playing a computer.

\subsection{Lessons Learned}

Perhaps the most important lesson to be learned from this section is the value to economists of making interdisciplinary connections to better understand the behavior of people. This includes anthropology, archeology, evolutionary psychology, game theory, cognitive psychology and behavioral economics, the cognitive neurosciences, computational mathematics, and economic history.

Figure 16 gives a flowchart that shows the interdisciplinary nesting of questions that make up a research program on personal exchange. This flowchart is developed in more detail in Houser, McCabe, and Smith (2003). A brief overview is as follows. 
Research Program In Neuroeconomics

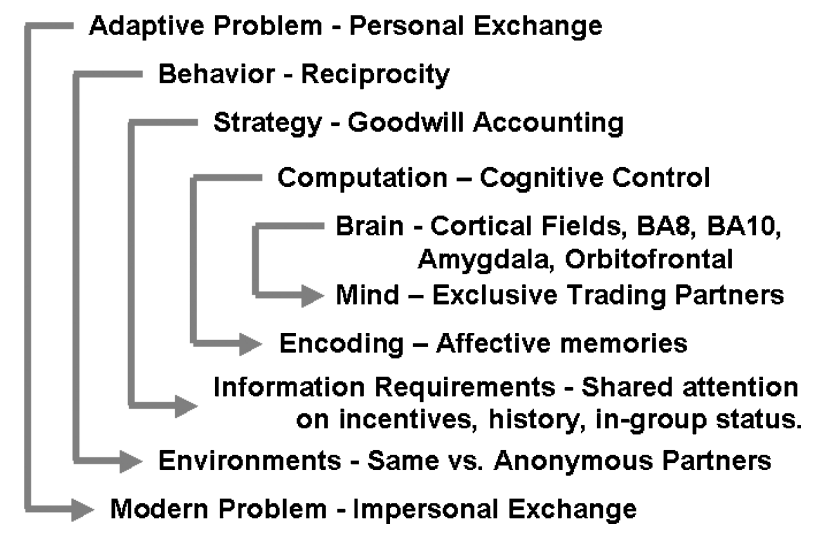

Figure 16. Research program in neuroeconomics.

The first step is to hypothesize an adaptive problem (personal exchange) that led to specialized brain circuitry in order to solve this problem. Next, explain how the adaptive problem has been transformed into the modern problem (impersonal exchange). The adaptive problem should lead to a behavior (reciprocity) that can be studied in both the adaptive (same partners) and modern (anonymous partners) environments. The behavior should be produced by a strategy (goodwill accounting) that requires certain information (shared attention, history/reputation, etc.) from the environment, information that can then be manipulated by experimental design. The strategy should be implemented as a set of computations (primary reinforcers and cognitive control) that depend on encoded information (sensory realizations of gains and loses; affective memories). These computations and encoding should then be located in cortical fields in the brain with capabilities and limitations that produce a mind with a capacity for trading with other minds.

There are five additional lessons to be learned from the data in this section. First, even individuals trained in game theory, and strategic thinking, will engage in trusting and trustworthy behavior. Second, trustworthiness increases when the game is simplified suggesting it is in part a function of common knowledge about intentions. Third, theory-of-mind predicts that when we control for the opportunity cost information embedded in the moves themselves we will (and experiments demonstrate we do) see differences in trustworthiness. Fourth, Goodwill accounting provides an account of reciprocal behavior in different environments and predicts certain types such as High Machs in the population. Fifth, the brain implements Goodwill accounting in a cortical system where prefrontal regions produce theory-of-mind activity that set up secondary inducers for cognitive control in frontal regions of the brain.

\section{Social Change: Studying the Dynamics of Social Order}

In this section we look at how reciprocity builds or deteriorates over time in environments that are more conducive to personal exchange (same pairing) and environments that are 
more conducive to impersonal exchange (random pairing.) This research becomes the first step in an experimental research program on social change.

\subsection{Extensive Form Reciprocity Games}

All of the comparisons to follow use the same extensive form bargaining tree structure, and either vary the payoffs in a controlled manner, or the matching protocol that assigns subjects to pairs, and to roles (player 1 or 2) in the bargaining tree.

In Figure 17, players 1 and 2 alternate moves, beginning with player 1, until a payoff box is reached. Player 1 receives the upper payoff, while player 2 receives the lower payoff. We simply note here that a move right at node $x_{6}$, in the right branch of the tree, results in the subgame perfect $(\mathrm{SP})$ noncooperative outcome $(40,40)$ for the one-shot game. In Game 1 a move left at node $x_{3}$ results in a symmetric cooperative (C) outcome in the left branch with payoffs $(50,50)$. If player 1 defects on player 2's attempt to achieve C, player 2 can punish such action by moving down at $x_{5}$, but this strategy is costly to 2 . Game 2 is formed from Game 1 by interchanging the payoffs $(50,50)$ with $(60,30)$ in the left branch of Game 1 ; consequently a move left at $x_{3}$ enables player 1 to defect without any risk of punishment.

Motivated originally by game theoretic reasoning we began our study with Game 1 . We soon explored Game 2 to determine how important the punishment option in Game 1 was for the achievement of cooperation.

In all repeat play protocols (except Repeat Single 1); subjects did not know how many trials would be executed before the end game. This was made credible by recruiting the subjects for two-hour sessions, and stopping after trial 20 which lasted on average one-hour.

Notice that games 1 and 2 implement negative and positive reciprocity games in a more complicated setting where there is always a competing subgame perfect outcome that is quite good. Thus these games are good tasks for experimental designs that are interested in the dynamics of cooperation over time.

McCabe, Rassenti, and Smith (1996), and McCabe and Smith (2003), provide a detailed description of the results from this game, but here we will only talk about the difference in

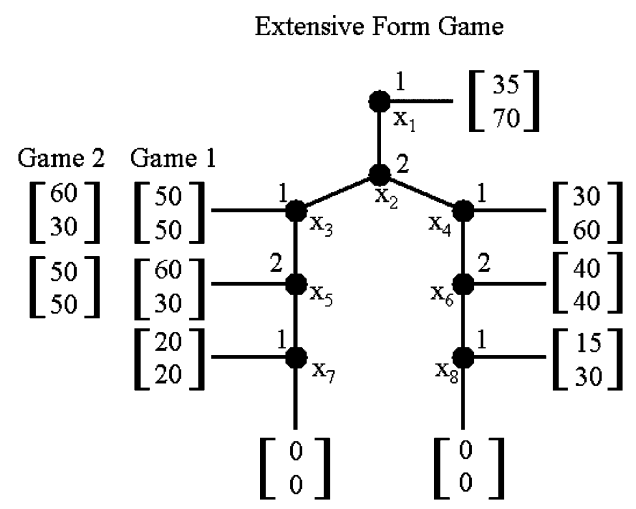

Figure 17. Extensive form game. 
Percentage of Cooperative Outcomes

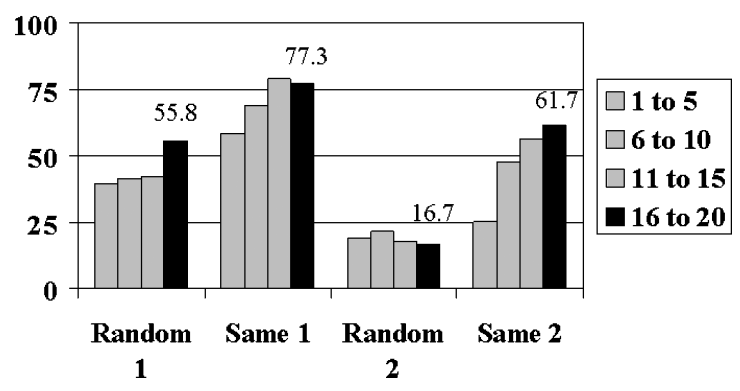

Figure 18. Percentage of cooperate outcomes.

the two games between same pairings where the same two people interact with each other over 20 periods compared to random pairing where each person plays a randomly picked partner each time. We refer to the combinations as Same1 (same pairing, game 1), Same2, Random1, and Random2. The results from experiments with 24 pairs of subjects are shown in Figure 18 where the percentage of $(50,50)$ outcomes is shown in five period intervals for each treatment.

As can be seen from the data, Game 1, which allows sanctioning, produces more (50, 50 ) outcomes than Game 2. Furthermore, same pairings produces more $(50,50)$ outcomes than random pairings.

\subsection{The Assurance Game}

Since same pairings with sanctioning seems to do best in promoting cooperation we decided to look at a game, called the assurance game, where subjects could choose whether to use positive or negative reciprocity to achieve cooperation. The resulting game is shown in Figure 19 and is discussed in detail in Hoffman, McCabe, and Smith (2003).

The low opportunity cost form of the game (LOC) has symmetric outcomes of 150 points to each player on both sides of the tree. The game is played as follows. Player 1 moves first at node $x_{1}$. He or she can either end the game, at a payoff of 0 points to each player, or move down, allowing player 2 to go left or right at node $x_{2}$. If player 2 goes left, the next option to player 1 is the same as it is on the right side of the tree: stop the game at 100 points to player 1 and 0 points to player 2 or move down at $x_{3}$. The interesting difference between the left and right sides of the tree comes with the next decision on the left side. If player 1 moves down at $x_{3}$, player 2 can either end the game at 150 points for each player or move down at $x_{5}$, thereby guaranteeing himself or herself 300 points. Thus, on the left side of the tree, player 1 should only move down at $x_{3}$ if he or she can trust that player 2 will move left instead of down at $x_{5}$.

If player 2 goes right, player 1 then has the option of stopping the game at 100 points to player 1 and 0 points to player 2, or moving down at $x_{4}$. Player 2 then has the option of stopping the game at 150 points to each player or moving down at $x_{6}$. If player 2 moves 


\section{The Assurance Game}

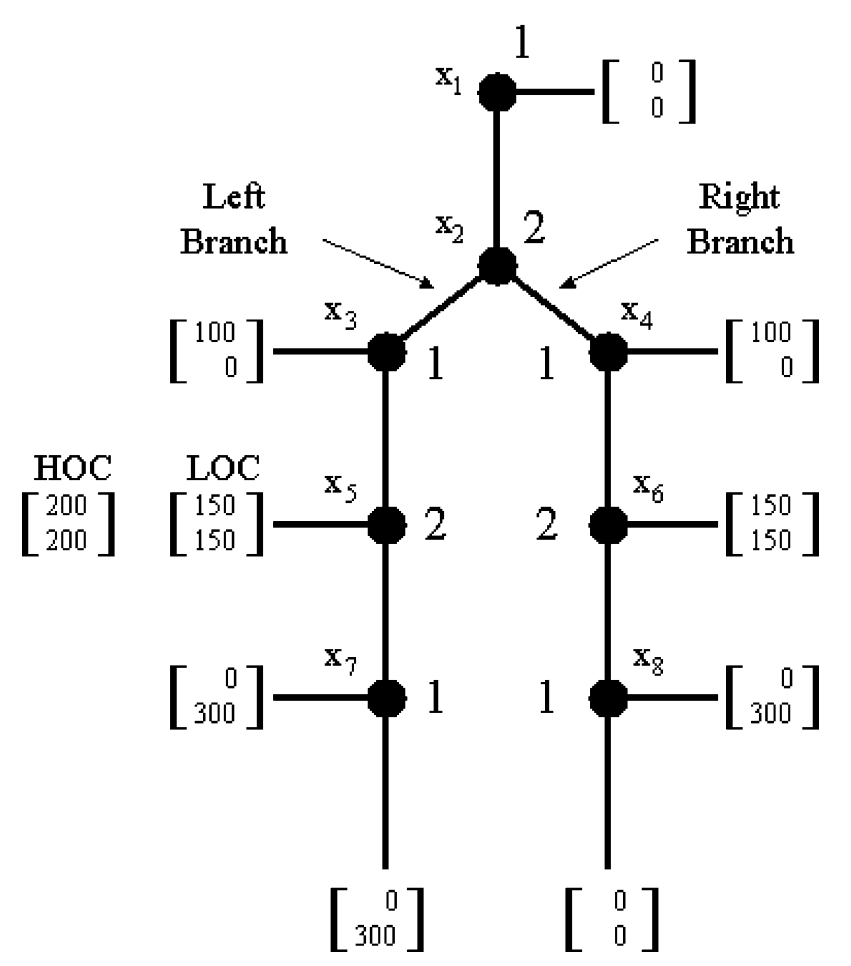

Figure 19. The assurance game.

down at $x_{6}$, player 1 has the option of stopping the game at either 0 points to each player or at 0 points to himself or herself and 300 points to player 1 . The punishment option, down at $x_{8}$, we interpret as being made possible by a third party enforcement mechanism. If player 1 plays "steal" (down at $x_{6}$ ), then player 1 can move to have the surplus confiscated by a third party (the experimenter).

Notice that cooperation to split the total possible payoff of 300 points can be achieved on either side of the game tree. However, cooperation on the left can only be achieved if player 1 is sufficiently trusting to move down at $x_{3}$ and player 2 is sufficiently trustworthy to move left at $x_{5}$. Cooperation on the right can be achieved by threat of punishment. If player 1 moves down at $x_{4}$ and player 2 does not move right at $x_{6}$, player 1 can punish player 2 at no cost.

Note, however, that cooperation by trust weakly dominates cooperation by threat of punishment. Comparing the right and left branches of the tree, the payoffs are the same at adjacent nodes except the bottom, where there are 300 more points available at $x_{7}$ than at $x_{8}$. The game involves assurance because a right move by player 2 at $x_{2}$ assures player 1 that it is not in player 2's interest to move down at $x_{6}$. No such assurance characterizes defection at $x_{5}$ on the left. 
In the high opportunity cost (HOC) form of the game, we introduce a payoff benefit associated with cooperation on the left. The payoff to each participant increases from 150 to 200 if they cooperate on the left instead of on the right. Alternatively, this benefit to cooperation on the left can be viewed as an opportunity cost associated with using a thirdparty mechanism to provide assurance that cheaters will be punished. In these treatments, we operationalize the cost associated with maintaining institutions for cooperation through threat of punishment in impersonal trade.

We repeat each game in two different ways to vary the degree to which goodwill accounting can be used to build social capital that sustains cooperation. In the personal exchange (PE) environment, players are paired with the same partner for 15 trials. In the impersonal exchange (IE) environment, each player plays exactly once with every other player. Thus, the game is repeated 15 times, but on each trial each player plays with a distinct other player. On each trial the role, player 1 or 2, is randomly assigned within each pair.

The data for the last five periods of this experiment is summarized in Figure 20. First, we show the percentage of left branch plays and the percentage of right branch plays made in each of our four cells, that is $\{\mathrm{LOC}, \mathrm{HOC}\} \times\{\mathrm{IE}, \mathrm{PE}\}$. Next we show the percentage of cooperative moves $(150,150)$ or $(200,200)$ made as a fraction of the number of total plays in each subbranch for each of the four treatments. Last we measure efficiency as the percentage of the maximum possible payoff that was actually attained in that treatment.

As can be seen in Figure 20, the high opportunity cost of using sanctions (HOC) results in less use of the right subbranch (compared to LOC) with a resulting loss of efficiency in both the personal exchange (PE) and impersonal exchange (IE) treatments, although more extreme in the IE case where for this treatment cooperation is not sustainable in the left subbranch. At the same time, holding opportunity cost constant, pairs always do better in the PE treatments relative to the IE treatments. From the percentage of cooperation statistics we see that subjects in the IE treatments always benefit from having the sanction/punish right hand branch, but they benefit more in the LOC condition. Comparatively, subjects in the PE treatments benefit very little since they seem to be adept at using trust to cooperate.

\subsection{Contract Failure and Reputations}

What happens to reciprocity in experiments involving more complex trading environments? To answer this question Houser, McCabe, and Oprea (2003) have recently started to look at random meeting bilateral bargaining markets each consisting of 6 buyers and 6 sellers. Each buyer has an induced value for one unit, and each seller incurs a unit cost. The supply and demand schedule is reproduced in Figure 21.

The experiment includes 18 rounds, each lasting 180 seconds, with subjects reassigned to new steps each round. Reassignment is conducted such that each subject will experience each step exactly three times but never consecutively. Each subject is randomly assigned to an anonymous partner each round. Subjects are allowed at any given moment (i) to offer/propose a contract price; (ii) to reject their partner's standing offer or (iii) to accept their partner's standing offer. Subjects can change their offer anytime before it has been accepted. This means that subjects can meet an unacceptable offer in two ways: (i) they can simply counter offer, leaving their partner's offer on the table or (ii) they can choose 


\section{Assurance Game Data \\ Last Five Periods $(\mathrm{N}=120)$}
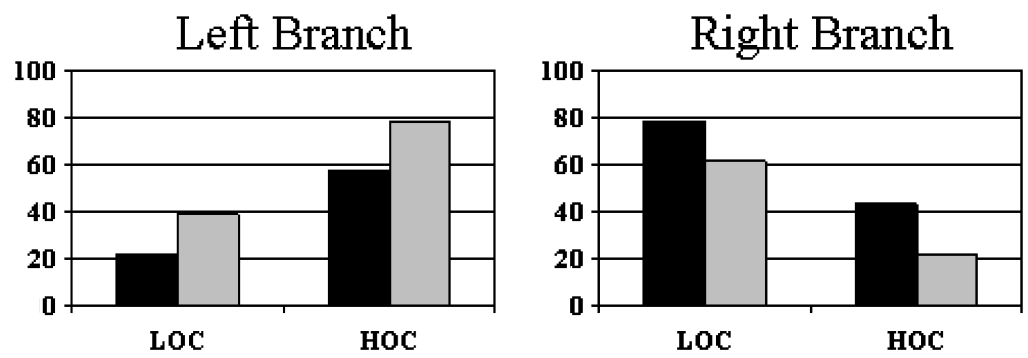

IE $\square$ PE
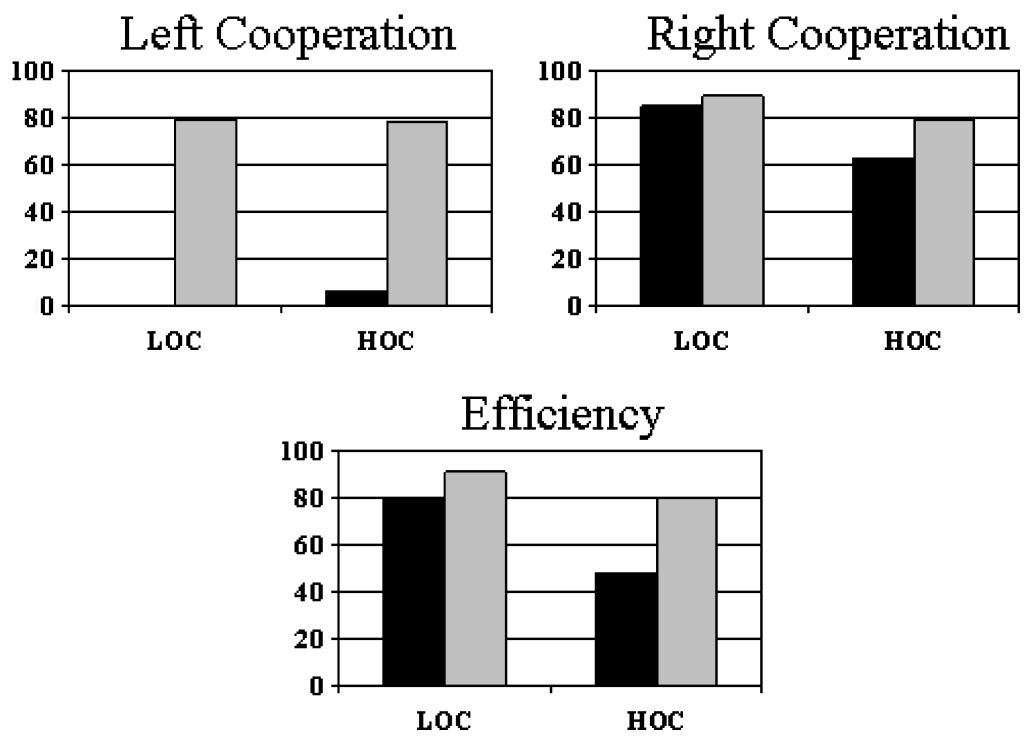

Figure 20. Assurance game data.

to explicitly reject their partner's offer. A contract is formed when one of the two subjects accepts their partner's offer.

Our treatment variable is the method of execution of contracts. In involuntary execution we follow the conventional practice in market experiments of executing contracts automatically. In voluntary execution subjects must independently choose whether or not to execute their contracts. Eight experiments (1-4 are the involuntary contracting and 6-8 are the voluntary contracting) were run.

Efficiency is calculated as the ratio of total surplus realized by trade behavior to the total surplus possible in the environment. Note that only a failure to form a contract can cause less 


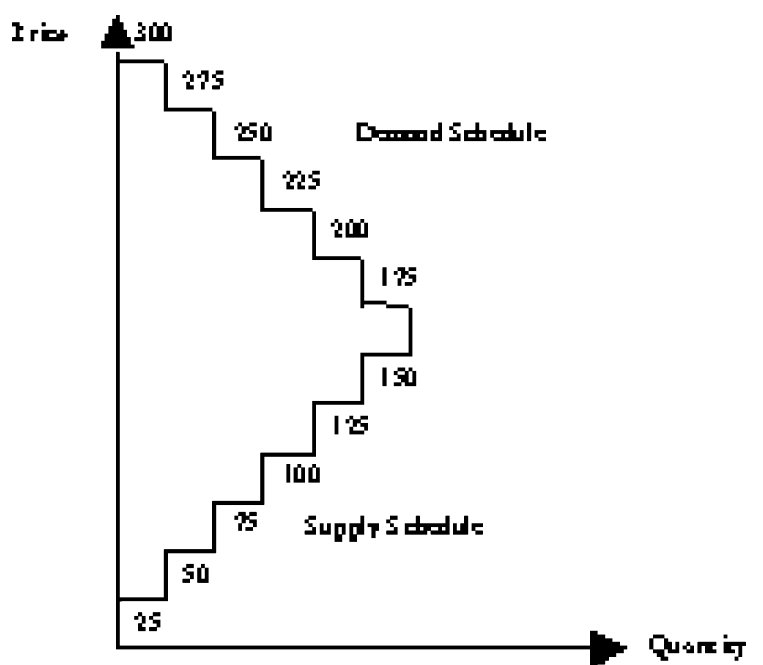

Figure 21. Supply and demand for random meeting bilateral bargaining market.

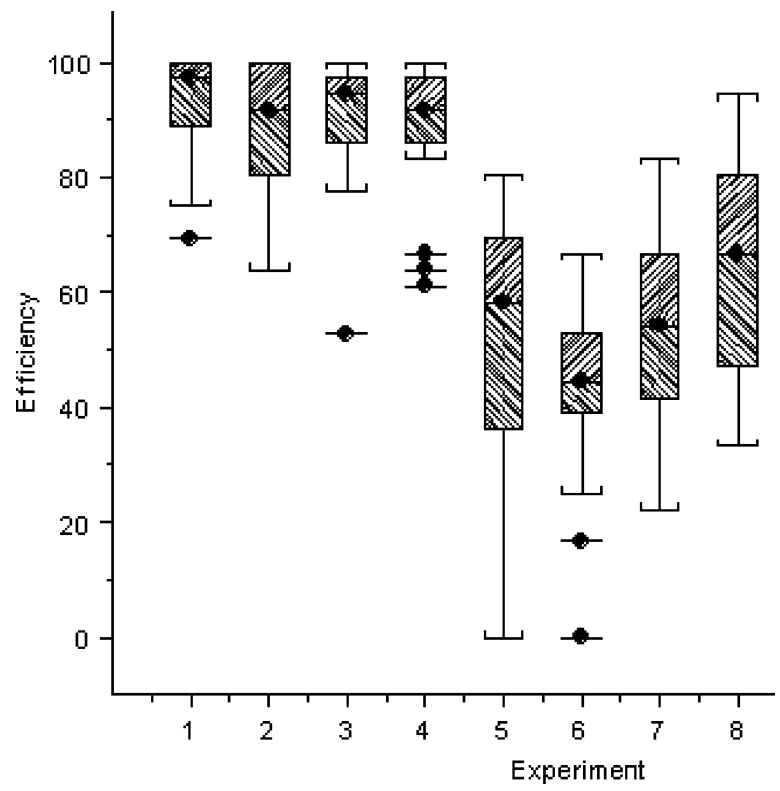

Figure 22. Box plot of round efficiencies by experiment.

than $100 \%$ efficiency in the involuntary contracting treatment. In the voluntary-contracting treatment, efficiency losses can be caused both by failures to contract and by failures to send units, i.e., execute. Box plots of efficiency are shown in Figure 22. For each experiment we have 18 rounds or observations. The Box plots show the median efficiency and inner and outer quartiles as well as outliers. 
In the Auto-Contracting treatment, equally weighted mean efficiency per round stays roughly constant throughout the experiment, and reaches near-perfect efficiency in some rounds. In the Manual Contracting treatment mean efficiency never rises above $70 \%$ and drops to $0 \%$ in a few rounds.

Reputation has long been of interest to economic theorists. Kreps and Wilson (1982) use reputation to resolve Selten's Chain-Store paradox. Kreps, Milgrom, Roberts, and Wilson (1982) use reputation to explain the cooperation observed in experimental studies of the finitely repeated Prisoners' dilemma game.

Our primary hypothesis is that adding a public reputation scoring mechanism to the manual contracting environment will move market efficiency towards the auto-contracting baseline. Most laboratory examinations of reputation effects, including all of those listed above, have used auction designs. However, interpreting auction experiments is made more difficult by the complicated, and largely unknown, way that number of bids and bidders interacts with bidders' reputations to generate final outcomes. An important advantage of our bilateral bargaining design is that the number of buyers is always fixed at one. This means that variation in outcomes can be traced more easily to variation in reputations.

In our reputation environment, a person's reputation relevant history can be summarized by three statistics: (a) the total number of contracts they have formed; (b) the total number of formed contracts they have executed; and (c) whether they executed a formed contract in the previous period. This last statistic captures a "recency" effect that some have argued is important, in the sense that people weight immediately previous behavior more heavily than other behavior when drawing inferences about someone's trustworthiness. Importantly, our experimental software calculates these statistics automatically. In particular, subjects do not have to manually report whether their trading partner formed or executed a contract.

A subject's history might be relevant both in an absolute and relative sense. For this reason, each subject is provided each of the above three statistics for every person in the experiment. They are also provided a detailed history for their current trading partner. This history indicates all of their current partner's decisions by round. Finally, they are always provided with a complete history of their own decisions by round.

Comparing the results of a baseline without reputation tracking to a treatment that includes reputation tracking allows inferences to be drawn about how reputation affects market outcomes. Figure 23 below shows the results from our public reputations treatment, last three box plots. As you can see reputations do increase economic efficiency by allowing more trades to be completed.

\subsection{Lessons Learned}

As we add an intertemporal element to the use of reciprocity in positive and negative reciprocity games, the sustainability of cooperation can now be studied in dynamic settings. Four lessons can be learned from the experiments summarized in this section. First, everything else being equal, cooperation is sustained best with same partners. Second, same partners will choose trust over sanctioning as a preferred way to organize their personal exchanges. Third, in impersonal exchange settings, that is, settings with random partners, 


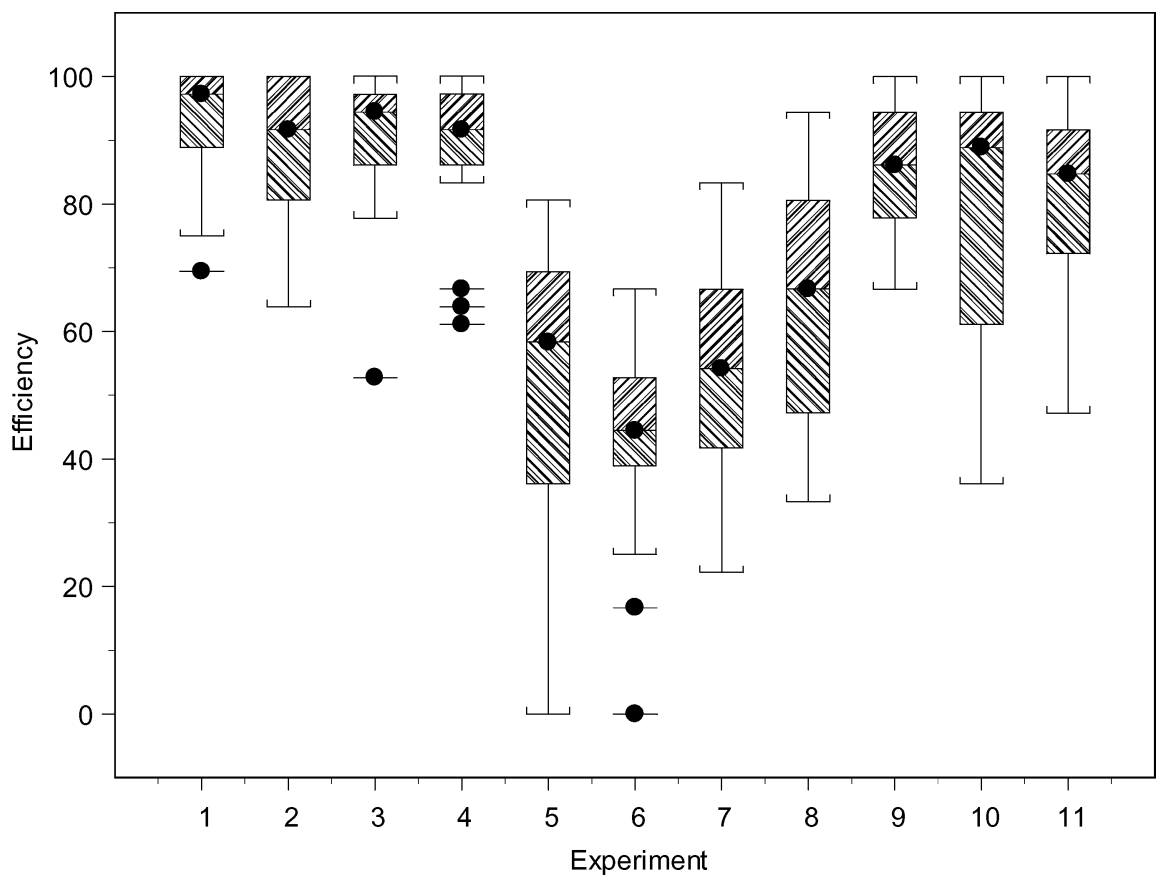

Figure 23. Public reputations treatment results.

exchange is improved with the use of sanctioning and reputations. Fourth, the value of sanctioning is mitigated by the opportunity cost of choosing sanctions.

Overall we can conclude that personal exchange mechanisms (such as same partners) competes very well, and seems to be preferred in many instances to the use of sanctions or reputations especially if these require additional costs to operate. Clearly, for sanctions and reputations to be adopted, individuals would have to see a clear benefit, above what can be accomplished from personal exchange alone, from doing so.

\section{Money Experiments}

Research on the role of money provides a nice example that ties together the topics from the earlier sections. As shown in Figure 24, in a personal exchange person A provides person B with some good or service denoted $G_{t}$, at time $t$. In return, person B provides person A with a promise to reciprocate with something of mutually agreed upon (maybe by implicit convention) equal value, denoted by $H_{t+1}$. When B reciprocates, A then completes the transaction by crediting B with 'good will.'

In general goodwill is risky because it depends on the trustworthiness of another individual in the future. To break away from these personal exchange conventions people had to develop a way to trade that didn't require such a strong reliance on other person's trustworthiness. One such invention was the use of money. 
Comparison of Personal and Monetary Exchanges
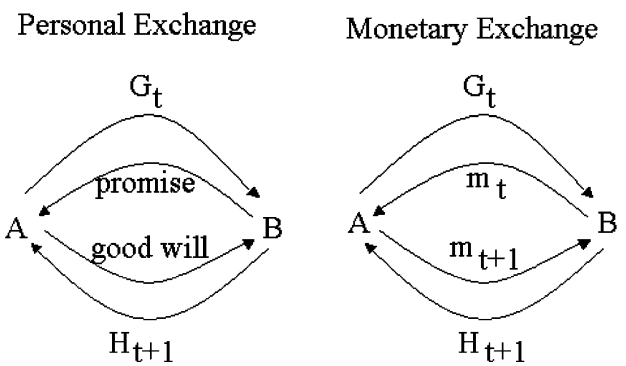

Figure 24. Comparison of personal and monetary exchanges.

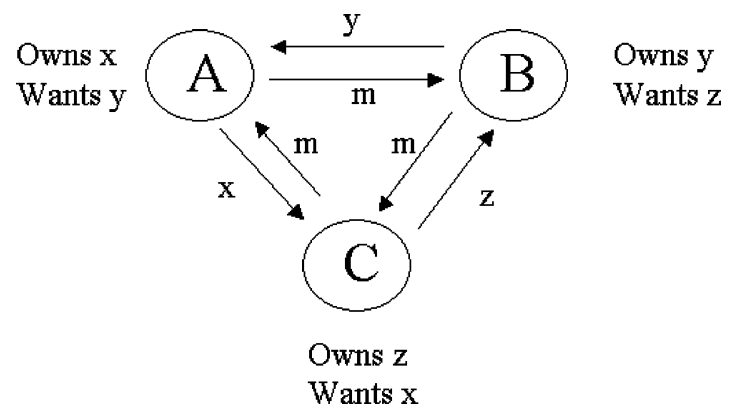

Figure 25. The role of money in reducing transactions costs.

In monetary exchange person A provides person B with some good or service, $G_{t}$, at time $t$. In return, person B provides person $A$ with an agreed upon amount of money, $m_{t}$. By making trade bilateral there is less default risk. Instead, most of the risk is now on the future value of money, which has a promissory component as a medium of exchange in future transactions. Note that B does not in general make this promise, but instead, someone that manages the money makes the promise. Good will need not be credited to complete these exchanges.

Economists have long recognized that another feature of money that makes it valuable is that it also reduces transactions costs associated with a double coincidence of wants. As shown in Figure 25 each person $\mathrm{A}, \mathrm{B}$, and $\mathrm{C}$ respectively desires $y, z$, and $x$, but owns $x, y$, and $z$. No one can make a bilateral trade that makes both players better off, for example A wants $y$ from B, but A only has $x$, which B does not want. Personal exchange could solve this problem by having one of the three persons act as a middleman in the trading, but playing the role of middleman adds risk. As shown, Money also solves the problem is suitable nominal prices can be found.

\subsection{Holding Fiat Money at Fixed Prices}

McCabe (1989) studies the use of fiat money in an economic environment, shown in Figure 26. In this environment there are six subjects with two subjects assigned each of the 
Economic Environment

\begin{tabular}{|c|c|c|c|c|c|c|}
\hline \multirow[b]{2}{*}{ Type } & \multicolumn{6}{|l|}{ Period } \\
\hline & 1 & 2 & 3 & 4 & 5 & 6 \\
\hline \multicolumn{7}{|c|}{ Part A: Bond endowments } \\
\hline $\begin{array}{l}\mathbf{A} \\
\mathbf{B} \\
\mathbf{C}\end{array}$ & $\begin{array}{l}1 \\
1 \\
0\end{array}$ & $\left.\begin{array}{l}0 \\
1 \\
1\end{array}\right\}$ & $\begin{array}{l}1 \\
0 \\
1\end{array}$ & $\begin{array}{l}1 \\
1 \\
0\end{array} 3$ & $\begin{array}{l}0 \\
1 \\
1\end{array} 3$ & $\begin{array}{l}1 \\
0 \\
1\end{array}$ \\
\hline \multicolumn{7}{|c|}{ Part B: Dividends } \\
\hline $\begin{array}{l}\text { A } \\
\text { B } \\
\text { C }\end{array}$ & $\begin{array}{r}50 \\
25 \\
0\end{array}$ & $\begin{array}{r}0 \\
50 \\
25\end{array}$ & $\begin{array}{r}25 \\
0 \\
50\end{array}$ & $\begin{array}{r}50 \\
25 \\
0\end{array}$ & $\begin{array}{r}0 \\
50 \\
25\end{array}$ & $\begin{array}{r}25 \\
0 \\
50\end{array}$ \\
\hline \multicolumn{7}{|c|}{ Part C: Ticket endowments } \\
\hline $\begin{array}{l}\mathbf{A} \\
\mathbf{B} \\
\mathbf{C}\end{array}$ & $\begin{array}{l}1 \\
0 \\
0\end{array}$ & $\left.\begin{array}{l}0 \\
0 \\
0\end{array}\right\rangle$ & $\left.\begin{array}{l}0 \\
0 \\
0\end{array}\right)$ & $\begin{array}{l}0 \\
0 \\
0\end{array}$ & $\left.\begin{array}{l}\mathbf{0} \\
0 \\
0\end{array}\right\rangle$ & $\begin{array}{l}\mathbf{0} \\
\mathbf{0}\end{array}$ \\
\hline
\end{tabular}

Figure 26. The use of fiat money in an economic environment.

three player roles A, B, C. Part A of the economic environment shows the allocation of one period bonds, to each type of player, at the beginning of each of six periods. For example in period 3, type $\mathrm{A}$ and $\mathrm{C}$ players each start with one bond, while type B players start with zero.

In Part B of Figure 26 we see what bonds are worth to each player type at the end of each period. So for example, in period three bonds are worth 25 cents to player A, 50 cents to player C, and zero to player B. Finally, in part C we see that type A players start with one ticket each. Tickets are different from bonds since they last all six periods, but have no end of period value. Thus tickets are the fiat money for this six period economy.

Notice that subjects could simply hold their bonds each period resulting in them each earning $\$ 1.50$. But, if they could trade, then subjects could get the following final allocation as shown by the arrows in Part A of Figure 26; type A subjects get 2 bonds (worth 50 cents each) at the end of periods 1 and 4 , and type $B$ and $C$ subjects each get 2 bonds at the end of periods 2, 5, and 3, 6 respectively. In this allocation, each subject would earn $\$ 2.00$. The arrows show a sequence of trades where each player at the arrowhead gets a bond and each player at the tail of the arrow gets a ticket.

Why are people willing to accept tickets when they have no value? The answer is obvious, by selling a 25 -cent bond for a ticket; they then get to buy a 50-cent bond. Of course, the problem is at the end. In period six, why would a type A player give up a 25-cent bond for a worthless ticket? The myopic self-interested answer is they shouldn't. But then, by backwards induction, player $\mathrm{C}$ should not give up his or her 25 cent bond in period 5, nor should player B in period 4 , and so one all the way back to period one. So in theory selling your 25-cent bond just sticks you with a worthless piece of paper, not a 50-cent bond in the future. 


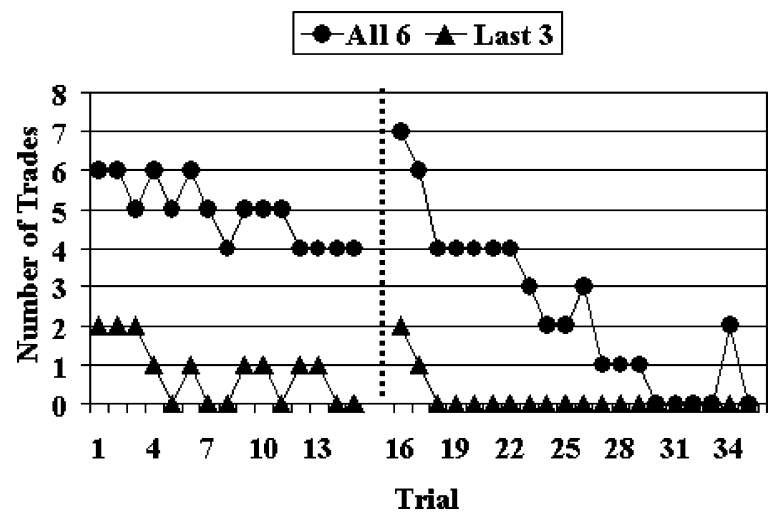

Figure 27. Results of fixed-price trading institution.

To test this hypothesis McCabe designed a fixed-price trading institution where bonds could be traded for tickets at the price of one bond for one ticket. He then ran the economy with the same subjects over a number of trials so that they would get experience with the fact that tickets were worthless in period six. The rather surprising results are shown in Figure 27. The first fifteen periods to the left of the dotted line show data for subjects who had previously been in the same experiment. The second twenty periods to the right of the dotted line shows data for the same subjects after they had been brought back a third time.

The circles indicate the total number of trades $(\max 12)$ within a six period trial, and the triangles show the total number of trades $(\max 6)$ for the last three periods. Notice that trade in the last three periods collapses as predicted by backwards induction, but in the first three periods subjects continue to trade until trial 30.

Is this persistence in trading in the first three periods due to very slow learning, or a continued desire to trade even as it becomes clear that using money is risky?

\subsection{Hyperinflations and Fiat Money}

Deck, McCabe, and Porter (2003) followed up on the fiat money experiment with fixed prices by considering fiat money in a double auction where the nominal prices of goods were now allowed to vary. They implemented a laboratory environment consistent with the circular flow diagram shown in Figure 28. In this environment there are three types of traders. Type A traders produce good A and consume good B while type B traders produce good B and consume good A. A third type of trader is government. Government consumes both goods $\mathrm{A}$ and $\mathrm{B}$ and produces money (tickets).

Goods A and B only last one experimental trading day (roughly 7 minutes) while money lasts for an experimental week (Consisting of some number of experimental days). Units of each good are bought and sold in simultaneous double-auction markets where bids and asks are in tickets, and contracts specify a number of tickets to be exchanged for a good. 

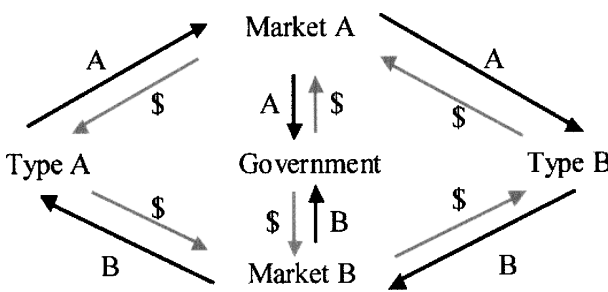

Figure 28. Fiat money in a double auction where nominal prices vary.

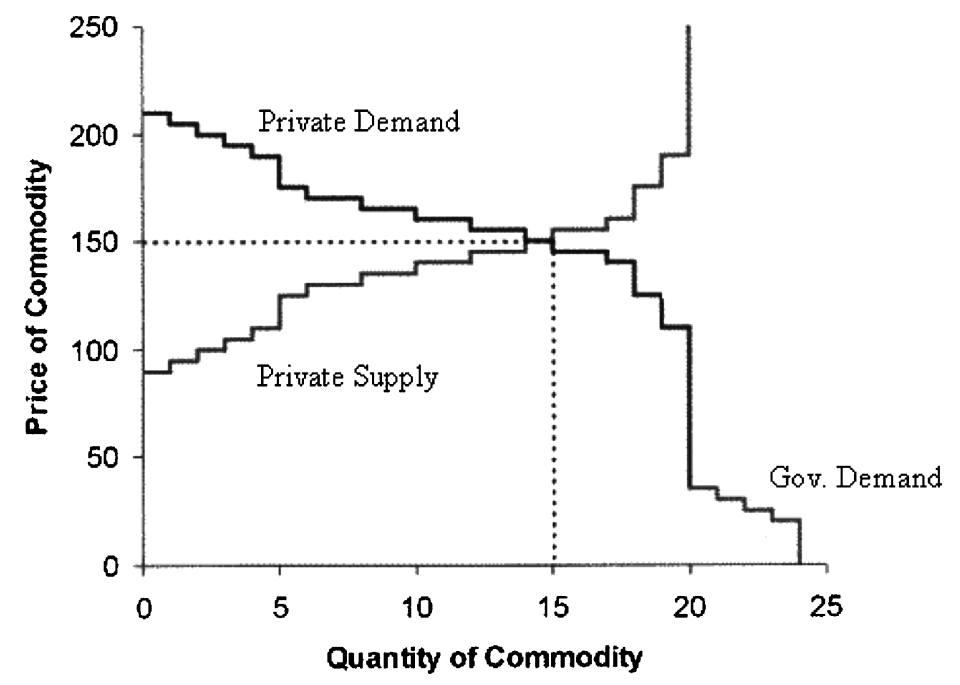

Figure 29. Supply and demand for goods A and B.

Sellers produce to order and pay a dollar (U.S. dollar) cost for each unit sold. Buyers earn dollars (U.S.) for each unit bought. Subjects start with an initial endowment of tickets and tickets carry over from day to day. If the tickets are backed then at the end of the week the experimenter pays one cent for each ticket owned. If the tickets are fiat the experimenter pays zero cents for each ticket owned.

At the beginning of each market days new values and costs are assigned to buyers according to the Supply and Demand curves shown in Figure 29. These curves are identical for both goods. Notice that government demand should never be satisfied in equilibrium, but by printing money government can crowd out private consumption.

At the end of each day U.S. dollars are earned based on final production and consumption of goods, and at the end of the week the tickets are exchanged and become worthless. A new week starts with a new allocation of tickets.

In the experiment subjects were all trained before participating in using fiat money (tickets) and contracting in double auctions. The results for a typical backed money experiment are shown in Figure 30. 


\section{Long Horizon with Backed Money}

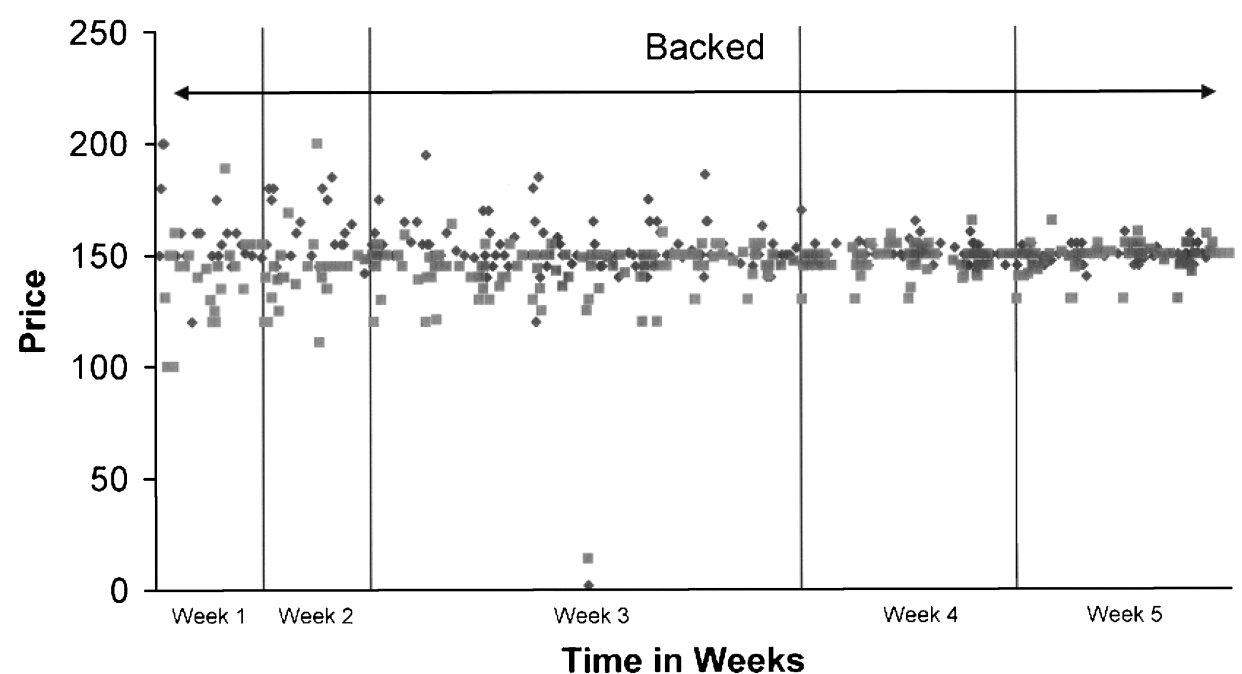

Figure 30. Long horizon with backed money.

The first two weeks each have two trading days. This is followed by a long week of ten trading days and then two shorter 4-day weeks. Prices in both markets are plotted together, and both markets converge to a predicted price of $\$ 1.50$ or 150 tickets reaching efficiencies over $90 \%$.

Figure 31 shows a typical market where the money is unbacked, and there is no Government player.

While there is slightly more price dispersion, prices are still converging nicely to 150 . We see little or no end of horizon effect in weeks 3 or 4 suggesting that the value of money did not unravel very much. Again efficiencies were fairly high at roughly $90 \%$.

In Figure 32 we introduce a government as two additional subjects who buy both goods $\mathrm{A}$ and $\mathrm{D}$ and print money (tickets), which end up in circulation.

As in previous experiments money was backed for the first two (two day) weeks, and then unbacked in week three. This graph is typical of our government experiments. In the first two weeks there is no problem using backed money. However, in week three, when the money is unbacked, we see our first serious hyperinflation with prices rising from 150 in day 1 to 5000 by the end of day 7 . Furthermore the number of trades is reduced dramatically causing real efficiency losses of over $50 \%$. This experience is remembered in week 4 with even more disastrous results. A program constraint only allowed prices to rise to 10,000 !

Is hyperinflation due to the government's active role as competitor for goods and services, or is it simply a consequence of expectations towards an increasing money supply as government prints new money to keep up with inflation? Figure 33 provides a partial answer to this question. In this experiment we removed the government players, and at the end of each day we added tickets to each subject's ticket account in order to achieve the 


\section{Long Horizon and No Government}

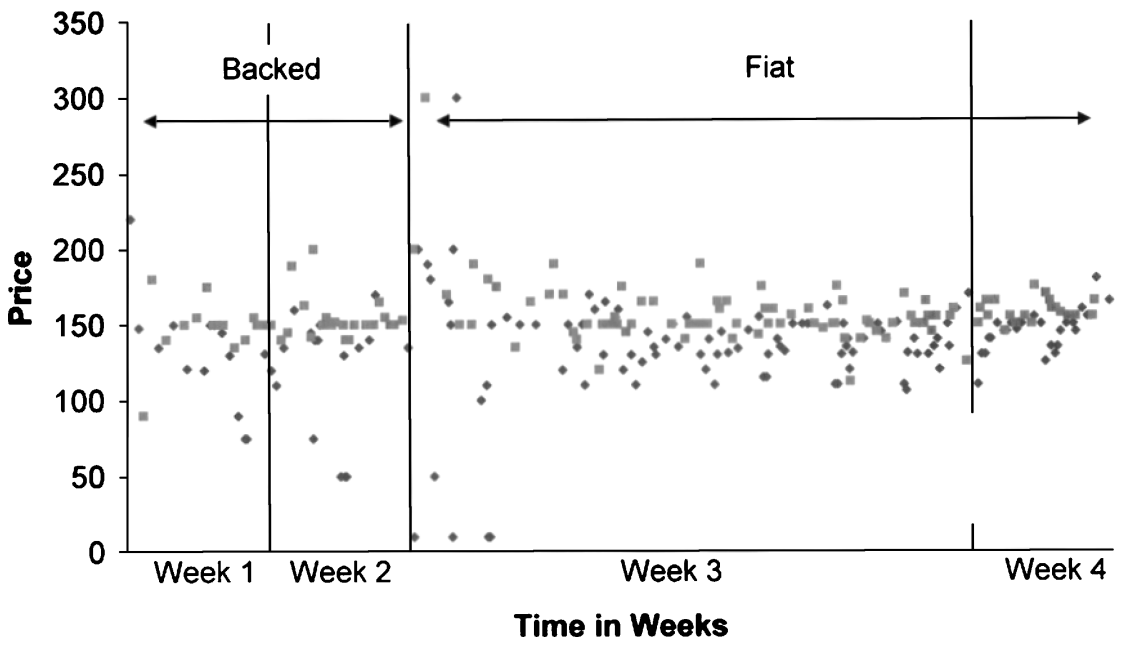

Figure 31. Long horizon and no government.

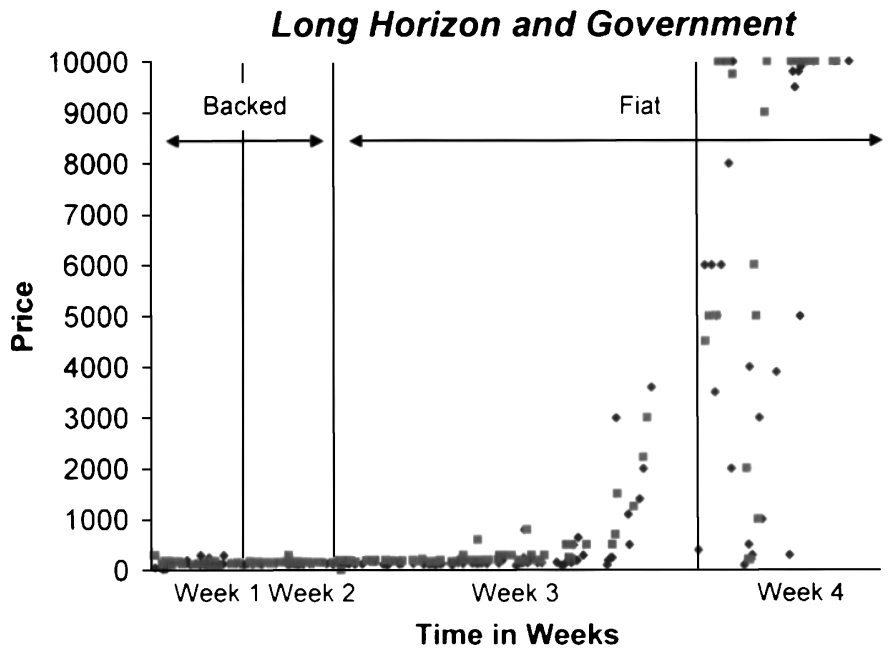

Figure 32. Long horizon and government.

same average increase in the money supply that we observed in the hyperinflations (with Gov.). As can be seen nominal prices inflate as the money supply increases, but they do so in a more orderly fashion. In fact, efficiency in these cases were much higher than efficiency with an active government suggesting that part of the seriousness of hyperinflations is due to the risk of crowding out the private sector by government policies. 


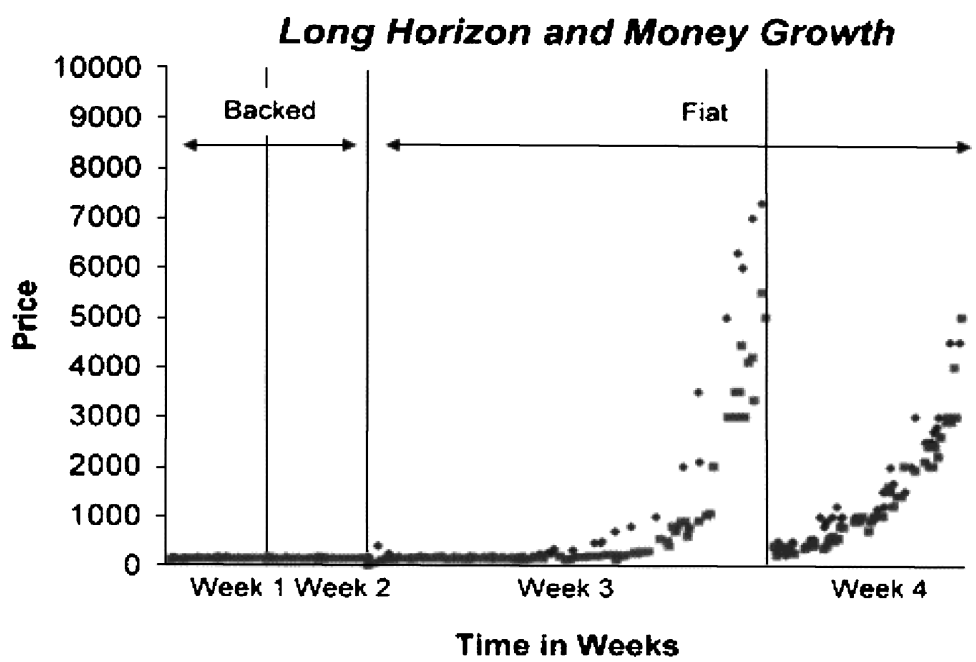

Figure 33. Long horizon and money growth.

\subsection{Lessons Learned}

Two important lessons come from these experiments. First, people are willing to use money, even when it is unbacked, and the value of doing so is seen as very risky. This suggests that the perceived value of using money is even higher. Second, government creates risks not only through its ability to print money, and thus cause nominal shocks, but also by its ability to crowd out the private sector thus causing real shocks. It may be this latter behavior that is more likely to be the cause of problems in serious hyperinflations.

\section{Implications for Economic Change}

What are the take home messages from experimental economics for economic change?

First, the default mode for economic behavior is personal exchange. This mode of behavior is supported by innate mental capacities such as mentalizing others, delay of gratification, and goodwill accounting, within an environment where historic and future interactions play an important role. These mechanisms operate by promoting exclusive, individual specific, trading relationships among compatible partners, and are influenced by the observability of individual behavior, and consequent reputations.

Second, economic progress can be seen in part as the development of social 'tools' that extend personal exchange to allow for the reduction of uncertainty and an increase in the scope of economic activity. The first such progress was likely the recognition of decision maker roles and the rights, and responsibilities that accrue to someone in this role. We see in experiments that assigning people, through some weakly legitimizing process, to these roles changes both the nature and outcomes from personal exchange. 
Culture plays an important role in defining these roles, and deciding who gets access, and social history can play an important role in increasing the scope of personal exchange. An interesting open question is how does social history get recorded? Furthermore, these rights must be defended, and it seems reasonable to expect that personal exchange is again the first mechanism for their defense. Clearly rewarding key people can help build a coalition of supporters for both the person currently in the role and for the role itself. Also a system of sanctions must be devised that punishes people appropriately for failure to either live up to their roles, or who attempt to attack, or diminish, other roles, or who fail to live up to commitments made in personal exchange.

Third, sanctioning systems are likely to be controlled by rules that determine who can be punished for what, how much they can be punished, and who will administer the punishment, and by what means. This is because sanctions may result in escalations and retaliations towards individuals that impose them, and therefore would more likely be preferred to be seen as impersonal by those that are using them. Similarly rewards systems are likely to be controlled by rules, especially when the rewards involve using other people's money.

Fourth, given the reliance on roles, the development of rules of law is an important step in depersonalizing economic exchange. However, as experiments have shown people will not always choose rules of law if they perceive it in their self-interest to engage in personal exchange. Thus, an important theme in experimental economics is than impersonal forms of exchange are built on our innate propensity for personal exchange.

Fifth, while economic theory helps us to understand what kind of economic change we wish to produce, it is not as helpful in telling us how to implement that change. As a consequence policymakers need to test bed their preferred implementation before going to the field. Economic Systems Design provides us with one approach. Here the experimental laboratory is used as a low cost tool to see how people will react to different implementations of the rules.

Sixth, to be useful to policymakers, Economic Systems Design will need to embed proposed design implementations in experimental environments that allow personal exchange to take place. But such an embedded experiment will have to take careful account of how the current system has adapted to the natural environment.

\subsection{How can Experiments be Useful to USAID in the Future?}

Ultimately the main value in experimental economics will be in using the experimental method to help policy makers introduce new institutions and/or organizational forms, or modify existing institutions and/or organizational forms, or work within existing institutions and organizational forms, to achieve some set of goals. While this could be done piecemeal by recruiting researchers from individual labs around the world as needed, it would be valuable to have one or more centers where such a research program can be pursued in a more synergistic approach.

Figure 34 provides one example flow chart of such a center based on the experience of the Interdisciplinary Center for Economic Science (ICES) at George Mason University (GMU). The main goal of the center is to use the experimental method to work fluidly back and forth between theory and practice (implementation). This is done though a connected set of 


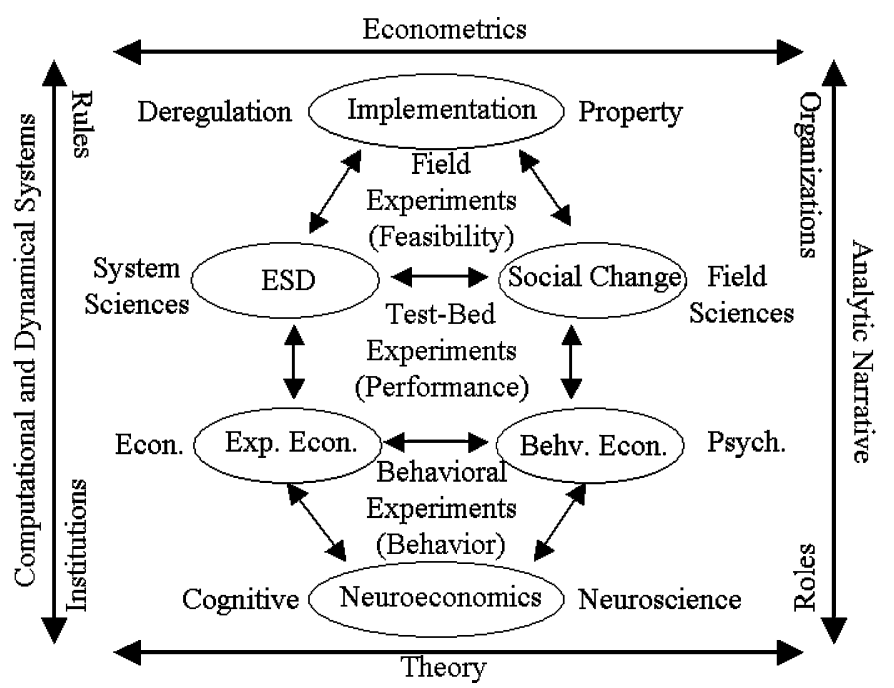

Figure 34. The contribution of experiments to policy.

experimental methodologies starting with behavioral experiments, see Smith (1982), where the main goal is to understand how individual behavior aggregates through institutions and organizations to produce outcomes that affect everyone.

As behavior is better understood it becomes possible to move to test-bed experiments, see McCabe, Rassenti, and Smith (1991), where the main goal is to study the performance, for example, allocative efficiency, of different instantiations of the rules (institutions) and roles (organizations) within given, but controlled, economic environments. Once an effective instantiation is found it can be field-tested in a field experiment. Here the main goal is to test the feasibility and scalability of the test-bed results in an uncontrolled economic environment, but where the experimenter is still able to design in comparison baselines.

One of the synergistic aspects of this research is that Field Experiments may necessitate additional test-bed experiments both in the design stage and in the analysis of results stage, while test-bed experiments may necessitate additional behavioral experiments both ex-ante and ex-post. Another synergetic feature is part of what makes good economic research as shown in the set of outer arrows in Figure 34. The top and bottom arrows remind us that experimental research should be informed by, and informing, economic theory, and built on sound statistical designs. This means that it should be possible to both, build a connected set of mathematical models across each level of experimentation, and to develop statistical methods where one level of experiments improves estimation and inference at another level.

The ellipses that surround the different experimental methods suggests the labs that need to be directly involved at each stage of experimentation, and outside the ellipse we show the main discipline that is recruited to inform the research. For example ICES has strong research labs in Experimental Economics, Economics Systems Design (ESD), and 
Neuroeconomics, and we have been working to build strength in Behavioral Economics, and Social Change. As can be seen in Figure 34, this means ICES has a strong Left Branch, which is connected synergistically through the use of computational and dynamical systems analysis, a strong sub discipline at GMU.

While the left branch emphasizes the study of institutions (as embodiments of the rules) is committed to do research on organizations (as embodiments of roles) since we believe that both research branches are necessary to do good research at every level. Theories that emerge from the laboratory would be incomplete without models of how institutions and organization interact, and implementation would be impossible without a thorough understanding of both.

We are working with the Krasnow Institute and the Department of Psychology at GMU to build a behavioral economics lab and we are working with the Mercatus Center and the College of Law at GMU to build a social change laboratory. We see the right hand branch of our center as being connected synergistically through the use of analytic narratives developed by Doug North in economic history, and Elinor Ostrom in her political-economy field studies.

Besides ICES there are currently at least four other centers that would be capable with additional funding to do this kind of research. Elinor Ostrom's center in Indiana, the CalTech/UCLA center in California, Ernst Fehr's center in Zurich, and the Amsterdam center. In addition to the approximate 2 million dollar annual budget for faculty, grad student administrative, and laboratory support already being invested at these centers, a well organized policy evaluation and implementation component would cost roughly an additional 2 million dollars a year.

\section{References}

Ameden, H., Gunnthorsdottir, A., Houser, D., and McCabe, K. (1998) "A Minimal Property Right System for the Sustainable Provision of Public Good." Unpublished Paper, University of California, Berkeley.

Baron-Cohen, S. (1995) Mindblindness: An Essay on Autism and Theory of the Mind. Cambridge, Mass.: MIT Press.

Berg, J., Dickhaut, J., and McCabe, K. (1995) “Trust, Reciprocity, and Social History." Games and Economic Behavior, 10: 122-142.

Brewer, M. and Crano, W. (1994) Social Psychology. St. Paul, Minnesota: West Publishing Co.

Burnham, T., McCabe, K., and Smith, V. (1998) "Friend-Or-Foe Intentionality Priming in an Extensive Form Trust Game." Journal of Economic Behavior and Organizations, 43: 57-73.

Coleman, J. (1990) Foundations of Social Theory. Cambridge, Mass.: Harvard University Press.

Cosmides, L. (1989) "The Logic of Social Exchange: Has Natural Selection Shaped How Humans Reason? Studies with the Wason Selection Task." Cognition, 31(3): 187-277.

Cosmides, L. and Tooby, J. (1992) "Cognitive Adaptations for Social Exchange.” In: Barkow, J., Cosmides, L., and Tooby, J. (Eds.) The Adapted Mind, pp. 163-228. New York: Oxford University Press.

Croson, R. (1998) “Theories of Altruism and Reciprocity: Evidence form Linear Public Good Games.” Unpublished Paper. University of Pennsylvania, Department of Operations and Information Management, The Wharton School.

de Waal, F. (1996) Good Natured. Cambridge, Mass.: Harvard University Press.

de Waal, F. (1997) “The Chimpanzee's Service Economy: Food for Grooming.” Evolution and Human Behavior, 18(6): 375-386 
Deck, C., McCabe, K., and Porter, D. (2003) “Hyperinflation in a Laboratory Economy.” Working Paper, George Mason University.

Dickhaut, J. and McCabe, K. (2003) “Trust, Reciprocity, and Reputations: Once Bitten Twice Shy.” Working Paper, George Mason University.

Forsythe, R., Horowitz, J., Savin, N. E. and Sefton, M. (1994) "Replicability, Fairness and Pay in Experiments with Simple Bargaining Games." Games and Economic Behavior, 6(3): 347-369.

Frith, U. 1989. Autism: Explaining the Enigma. Oxford: Blackwell.

Gunnthursdottir, A., McCabe, K., and Smith, V. (2002) "Using the Machiavellian Instrument to Predict Trustworthiness in a Bargaining Game." Journal of Economic Psychology, 23: 49-66.

Güth, W., Schmittberger, R., and Schwarze, B. (1982) "An Experimental Analysis of Ultimatum Bargaining." Journal of Economic Behavior and Organization, 3(4): 367-388.

Hayek, F. A. (1952) The Sensory Order. Chicago: University of Chicago Press.

Hayek, F. A. (1973) Law, Legislation, and Liberty, Vol I, Rules and Order. Chicago: University of Chicago.

Hayek, F. A. [1976 (1991)] “Adam Smith (1723-1790): His Message in Today's Language.” In: The Trend of Economic Thinking, pp. 119-124. Chicago: University of Chicago Press.

Hayek, F. A. [1984 (1978)] “Competition as a Discovery Process.” In: Nishiyama, C. and Leube, K. R. (Eds.) The Essence of Hayek, pp. 254-265. Stanford: Hoover Institution Press.

Hayek, F. A. (1988) The Fatal Conceit. Chicago: University of Chicago Press.

Hoffman, E., McCabe, K., Shachat, K., and Smith, V. (1994) "Preferences, Property Rights, and Anonymity in Bargaining Games," Games and Economic Behavior, 7: 346-380.

Hoffman, E., McCabe, K., and Smith, V. (1996a). "On Expectations and the Monetary Stakes in Ultimatum Games.” International Journal of Game Theory, 25(3): 289-301.

Hoffman, E., McCabe, K., and Smith, V. (1996b) "Social Distance and Other-Regarding Behavior in Dictator Games." American Economic Review, 86: 653-660.

Hoffman, E., McCabe, K., and Smith, V. (1998) "Behavioral Foundations of Reciprocity: Experimental Economics and Evolutionary Psychology." Economic Inquiry, 36(3): 335-352.

Hoffman, E., McCabe, K., and Smith, V. (2000) "The Impact of Exchange Context on the Activation of Equity in Ultimatum Games." Experimental Economics, 3: 5-9.

Hoffman, E., McCabe, K., and Smith, V. (2003) "What Makes Trade Possible?" Working Paper.

Hoffman, E. and Spitzer, M. (1985) "Entitlements, Right and Fairness: An Experimental Examination of Subject's Concepts of Distributive Justice.” Journal of Legal Studies, 14: 259-297.

Houser, D., McCabe, K. and Oprea, R. (2003) "Voluntary Contracting, Contract Failure, and Reputations." Working Paper, George Mason University.

Isaac, R. M. and Walker, J. (1988) "Communication and Free-Riding Behavior: The Voluntary Contributions Mechanism.” Economic Inquiry, 26(4): 585-608.

Kurzban, R., McCabe, K., Smith, V., and Wilson, B. (2001) "Incremental Commitment and Reciprocity in a Real Time Public Goods Game.” Personality and Social Psychology Bulletin, 27: 1662-1673.

Leslie, A. M. (1987) "Pretence and Representation: The Origins of 'Theory of Mind'." Psychological Review, 94(4): 412-426.

McCabe, K. (1989) "Fiat Money as a Store of Value in an Experimental Market." Journal of Economic Behavior and Organizations, 12: 215-231.

McCabe, K. and Smith, V. (2000) "A Two Person Trust Game Played by Naïve and Sophisticated Subjects." Proceedings of the National Academy of Sciences, 97(7): 3777-3781.

McCabe, K. and Smith, V. (2001) "Goodwill Accounting in Economic Exchange.” In: Gigerenzer, G. and Selten, R. (Eds.) Bounded Rationality: The Adaptive Toolbox, pp. 319-342. Cambridge, MA: MIT Press.

McCabe, K., Rassenti, S. and Smith, V. (1992) "Designing Auction Institutions: Is Double Dutch the Best?" The Economic Journal, 102: 9-23.

McCabe, K., Rassenti, S., and Smith, V. (1996) "Game Theory and Reciprocity in Some Extensive Form Bargaining." Proceedings National Academy of Sciences, 93(23): 13421-13428.

McCabe, K., Rassenti, S., and Smith, V. (1998) "Reciprocity, Trust and Payoff Privacy in Extensive Form Bargaining." Games and Economic Behavior, 24: 10-24.

McCabe, K., Smith, V., and LePore, M. (2000) "Intentionality Detection and "mindreading": Why does game form matter?" Proceedings of the National Academy of Sciences, 97: 4404-4409. 
North, D. (1990) Institutions, Institutional Change and Economic Performance. Cambridge, Mass.: Cambridge University Press.

Smith, V. (1965) "Experimental Auction Markets and the Walrasian Hypothesis." Journal of Political Economy, 73(4): 387-393.

Smith, V. (1982) "Microeconomics Systems as an Experimental Science." American Economic Review, 72(8): 923-955.

Smith, V. (1998) “The Two Faces of Adam Smith.” Southern Economic Journal, 65(1): 1-19. 